\title{
LA SOLUCION JUDICIAL DE CONTROVERSIAS ENTRE ESTADOS
}

María Teresa Infante Caffi

\section{PARTE I}

1. La función del Derecho Internacional en la solución de controversias

La solución de las controversias entre Estados es un capítulo básico en el estudio de los diversos medios que poseen los sujetos de Derecho Internacional para asegurar la aplicación de las normas de derecho, para lograr el ajuste de sus intereses y de situaciones, así como para restaurar la vigencia del orden internacional. Este estudio debe complementarse con el examen de los mecanismos de prevención y de disuasión del quebrantamiento del Derecho, incluyendo las diversas formas de control de la sanción internacional.

Las controversias internacionales pueden presentar un doble carácter político y jurídico. Todo análisis de esta materia debe partir de la constatación de que una controversia internacional siempre es política, en la medida en que encuentra su origen en oposiciones de intereses entre Estados y, como consecuencia de esto pueden presentarse conflictos de las políticas seguidas en defensa de la promoción de esos intereses. Estos dos elementos componentes de toda controversia pueden aparecer en diferentes combinaciones.

Por una parte, algunas controversias políticas pueden ser formuladas en términos jurídicos, como ha sido frecuentemente el caso en diferendos territoriales en los cuales se discute la existencia $y$ el valor de los títulos invocados por las partes. Por otra parte, el debate acerca de la existencia de una norma o del derecho de un Estado a adoptar ciertas decisiones o medidas puede dar origen a una controversia de carácter político, agravada por una insuficiencia o contradicción de la misma norma o del Derecho. 
La función que cumple el Derecho Internacional en esta materia, no depende en consecuencia, exclusivamente de la naturaleza de su objeto sino que además de la actitud de las partes. Dos instrumentos básicos de solución de controversias permiten observar distintas formas de operar del Derecho Internacional. Estos son, el acuerdo internacional logrado mediante una negociación directa $u$ otro procedimiento diplomático, o la solución que proviene de la decisión de un tercero y que se impone a las partes aplicando normas de Derecho Internacional.

En el primer caso indicado, los procedimientos a utilizar para lograr el acuerdo suponen una serie de acuerdos parciales y previos. Entre éstos, acerca de la existencia de la controversia y su objeto; sobre el interés y la urgencia de solucionarlo; sobre el procedimiento de negociación; el orden en que deben examinarse los asuntos negociables, etc. Un esfuerzo de negociación con mediación de terceros ofrece la crisis centroamericana, las acciones del Grupo Contadora y de Apoyo y el Acuerdo de Paz, de agosto de 1987.

En cambio, tratándose de una solución dictada por un tercero, se supone que las partes aceptan anticipadamente acatar la decisión como una solución definitiva. En la época actual, el arbitraje y la solución judicial internacional implica que las partes confieran jurisdicción a un órgano internacional, que actúa conforme a un procedimiento preestablecido y se reconozcan el derecho recíproco de presentar sus prucbas y argumentos en un pie de igualdad, a fin de lograr un pronunciamiento definitivo basado en el Derecho, salvo acuerdo en contrario y expreso de las mismas partes.

2. El Concepto de Controversias y los alcances de la distinción entre Controversias Politicas y Juridicas

El concepto de "controversia" es de naturaleza técnica. La jurisprudencia internacional ha rechazado emitir una decisión respecto de asuntos que no posean los elementos de una controversia. En el caso del Camerún Septentrional (I.C.J. Reports 1963, 33-34), la Corte Internacional de Justicia resolvió que no existía controversia, precisando que "el fallo de la Corte debería tener algunas con- 
troversias prácticas en el sentido que pueda afectar derechos $\mathrm{u}$ obligaciones existentes eliminando de esta manera la incertidumbre de sus relaciones jurídicas. En este caso, ningún fallo respecto del fondo, satisfacería estos clementos esenciales de la función judicial". En este asunto, se solicitaba que la Corte Internacional de Justicia interpretara un acuerdo constitutivo de fideicomiso de $\mathrm{Na}$ ciones Unidas, no vigente; el demandante tampoco pedía reparación.

En el asunto de los Ensayos Nucleares entre Australia y Nueva Zelandia contra Francia (I.C.J. Reports 1974, 270-271), la C.I.J. señaló que las declaraciones o promesas de Francia en el sentido de que no realizaría más ensayos nucleares en la atmósfera, significaban el cese de la controversia objeto de la demanda. En este caso, algunas opiniones disidentes manifestaron su disconformidad con el fallo señalando que existía una controversia jurídica relativa a los derechos de los Estados involucrados (IBID, 366).

En este sentido, la definición más corriente de controversia es la que expuso la Corte Permanente de Justicia Internacional (C.P.J.I. en el asunto Mavrommatis:

"Una controversia es un desacuerdo sobre un punto de derecho o de hecho, una contradicción de tesis jurídica o de intereses entre dos personas" (C.P.J.I. Serie A W2, p. 11).

Una distinción básica ha sido postulada frecuentemente por la doctrina y la práctica internacional, las que reconocen la existencia de controversias jurídicas y controversias políticas. Las primeras serian susceptibles de ser solucionadas aplicando el derecho vigente y las segundas serían aquéllas basadas en una pretensión cuya solución requiere de una modificación del derecho vigente. Lauterpacht, $H$. (The Function of Law in the International Community, 1933, p. 19-20) postuló la teor ía de los derechos jurisdiccionales, diferentes de los no-jurisdiccionales, sobre la base de las siguientes categor ́as:

- las controversias jurídicas son aquellas susceptibles de una solución judicial mediante aplicación de las reglas existentes y verificables de Derecho Internacional: 
- aquéllas en las cuales el objeto principal de la reclamación se refiere a cuestiones de importancia secundaria que no afectan a los intereses vitales de los Estados o su independencia política, o su soberanía interna o integridad territorial, $u$ honor, o cualquier otros intereses importantes a los que se refieren generalmente las cláusulas de reserva o restrictivas en las convenciones de arbitrajes;

- aquéllas en las cuales la aplicación de reglas existentes de Derecho Internacional son suficientes para augurar un resultado que no es incompatible con las demandas de justicia entre'los Estados y con un desarrollo progresivo de las relaciones internacionales;

- aquéllas relativas a derechos existentes en vez de versar sobre reclamaciones tendientes a un cambio en las normas de derecho vigente:

Estas categorías fueron postuladas con el fin de extender la competencia de los tribunales internacionales. En la práctica, salvo el caso de tribunales funcionales, el recurso a las jurisdicciones internacionales continúa siendo excepcional.

La distinción entre controversias "jurisdiccionales" o "judiciales" y "no-judiciales" se ha empleado como un medio para limitar el campo de operación de recurso judicial internacional. Esta distinción se encuentra incorporada de manera implícita en algunas convenciones internacionales que establecen mecanismos para la solución pacífica de las controversias. Asi, por ejemplo, el Art. 36 , inciso $2^{\circ}$ del Estatuto de la Corte Internacional de Justicia señala que la jurisdicción de la Corte se extiende a "todas las controversias de orden jurídico".

El Acta General revisada de 1949 contiene a su vez una referencia a controversias jurídicas como aquéllas en las cuales las partes se contestan reciprocamente un derecho. Art. 17 ("All disputes with regard to which the parties are in conflict as to their respective rights").

De una larga lista de convenciones y tratados que relacionan 
los mecanismos para la solución pacífica con la naturaleza de la controversia, puede destacarse: Las controversias de La Haya de 1899 y de 1907; los Pactos de Locarno de 1925, entre Alemania y Bélgica, Francia, Checoslovaquia y Polonia; los Tratados concluidos por Estados Unidos con Francia y otros Estados en 1928; el Acta General para la Solución Pacífica de Controversias Internacionales, de 1928, que contenía una regla en favor de arbitraje de toda controversia en la cual las partes no se discutieran recíprocamente un derecho, y a falta de acuerdo al cabo de un procedimiento de conciliación.

En caso de silencio del compromiso o a falta de éste, señala el Acta General de 1928, el Tribunal arbitral aplica las reglas de Derecho Internacional enumeradas en el Art. 38 del Estatuto de la C.I.J. Si estas reglas no existiesen, el tribunal juzga ex aequo et bono (Cap. III). Esta disposición es retomada en el Acta General revisada de 1949 y es indicativa de la distinción expuesta. El Tratado Americano de Soluciones Pacificas "Pacto de Bogotá", de 1948, expone una posición similar en el Art. XXXVIII, por el cual "las Altas Partes Contratantes tendrán la facultad de someter al arbitraje, si se pusiesen de acuerdo en ello, las diferencias de cualquier naturaleza, sean o no jurídicas, que hayan surgido o surgieren en lo sucesivo entre ellas". En todo caso, no se le reconoce al tribunal arbitral la competencia para juzgar ex aequo et bono.

Examinado el tema en la jurisprudencia internacional, se constata una regularidad en la tesis de que no existe a priori una controversia exclusivamente juridica o politica. La C.I.J. en el Asunto de los Rehenes en Teherán (Reports 1980, pp. 19-20) expresó que "ninguna disposición del Estatuto o del Reglamento le prohibe conocer de una controversia por la simple razón de que ésta comprendería otros aspectos, aunque fuesen muy importantes". Respecto de la posición de Irán en este asunto, la C.I.J. sostuvo que nunca "nadie ha pretendido, que dado que una controversia juridica sometida a la Corte constituye un aspecto de una controversia política, la Corte debe inhibirse de responder en interés de las partes, las cuestiones jurídicas que la oponen...; si la Corte, contrariamente a su constante jurisprudencia, a ceptara tal concepto, resultaria de éste una considerable e injustificada restricción de su función en materia de solución pacífica de las contro- 
versias internacionales". En el Asunto de las Actividades Militares y Paramilitares en y contra Nicaragua (I.C.J. Reports 1984, p. 439), la Corte confirmó ese principio, frente a los argumentos de EE.UU. entre otros acerca que la controversia debía ser planteada ante el Consejo de Seguridad de la ONU y que existían otros procedimientos diplomáticos en curso, como el Grupo Contadora. más apropiados para resolver asuntos que involucran el uso de la fuerza.

Sin embargo, por voluntad de los propios Estados, puede restringirse el alcance del concepto de "controversias jurídicas" o "justiciables", en el ámbito de un tratado o convención internacional que le confiere jurisdicción a una Corte o Tribunal o, en ciertos casos, mediante una declaración unilateral formulada de acuerdo con el Art. 36 inc. $2^{\circ}$, del Estatuto de la Corte Internacional de Justicia. Por ej. el Art. II del Tratado de No Agresión, Conciliación, Arbitraje y Arreglo Judicial entre la República de Colombia y los Estados Unidos de Venezuela de 1939 reconoce una excepción en la aplicación de los medios de solución para las controversias "que atañen a los intereses vitales, a la independencia o a la integridad territorial de los Estados Contratantes".

Un alcance especial tuvo la denominada "cláusula constitucional" insertada en tratados celebrados por Argentina y otros Estados. Así, el Art. 1 del Tratado General sobre Solución Judicial de Controversias con Chile, 1972, no-vigente, señalaba "Las Altas Partes Contratantes se obligan a someter a la jurisdicción de la Corte Internacional de Justicia todas las controversias de cualquier naturaleza que por cualquier causa surgieren entre ellas, en cuanto no afecten a los preceptos de la constitución de uno u otro país y siempre que no puedan ser solucionadas mediante negociaciones dir ectas".

En una categoría especial, deben considerarse las convenciones concluidas por Estados en un estrecho marco de cooperación y que amplían el ámbito de las controversias justiciables, otorgando competencia facultativa u obligatoria a una Corte permanente. Es el caso de la Corte Europea de Derechos Humanos (1950), la Corte de Justicia de la Comunidad Económica Europea (1957) y la Corte Interamericana de Derechos Humanos (1969), entre otros. 
3. La obligación de solucionar pacificamente las controversias in ternacionales

\section{- Las obligaciones fundamentales}

La Carta de la ONU contiene en su Art. 2, inc. $3^{\circ}$ un principio general, en virtud del cual "Los miembros de la Organización arreglarán sus controversias internacionales por medios pacificos, de tal manera que no se pongan en peligro la paz y la seguridad internacionales ni la justicia. Este principio es corolario del Art. 2, inc. $4^{\circ}$ de la Carta que prohibe la amenaza o el uso de la fuerza (Los Miembros de la Organización, en sus relaciones internacionales se abstendrán de recurrir a la amenaza o al de la fuerza contra la integridad territorial o la independencia política de cualquier Estado, o en cualquier otra forma incompatible con los Propósitos de las Naciones Unidas).

Su antecedente se encuentra en el Pacto Briand-Kellog. de 1928. La Resolución 2625 (1970) (Declaración sobre los principios de derecho internacional referentes a las relaciones de amistad y a la cooperación entre los Estados de conformidad con la Carta de las Naciones Unidas) recoge ambos principios, cuya naturaleza los califica como normas imperativas o de jus cogens.

Estos principios implican una gran cvolución del Derecho Internacional si se tiene en cuenta el alcance de las normas de la Convención de La Haya de 1907 para la Solucióin de los Conflictos Internacionales. Su Art. $1^{\circ}$ se refiere a que "Para evitar en lo posible recurrir a la fuerza en las relaciones entre los Estados, las Potencias signatarias convienen en emplear todos sus esfuerzos para asegurar el arreglo pacifico de las controversias internacionales". El uso de la fuerza no estaba todavía proscrito como medio de solución.

En un sentido similar, el Pacto de la Sociedad de las Naciones, en su Art. 12 indicaba que:

"Todos los miembros de la Sociedad convienen que, si surge entre ellos una diferencia susceptible de entrañar una ruptura, la someterán al procedimiento de arbitraje o a un arreglo judicial o al examen del Consejo. Convienen, ade- 
más, que en ningún caso deberian recurrir a la guerra antes de la expiración de un plazo de tres meses después de la decisión arbitral o judicial o del informe del Consejo". De conformidad con los Arts. 13, $\mathrm{N}^{\circ} 4$ y $15 \mathrm{~N}^{\circ} 6$, los miembros de la Sociedad se comprometían a no recurrir a la guerra contra otro miembro del organismo, que se sometiere a una sentencia arbitral o judicial que resolviere la controversia, o acatara los términos del informe del Consejo de la Sociedad de las Naciones.

El corolario de las disposiciones de la Carta de la ONU y de las Declaraciones ulteriores, incluyendo la de Manila de 1982 (Res. 37/10) para la Solución Pacífica de las Controversias (I.L.M. XXI, 1982, 2, pp. 449-455), es un deber de prevención, que el Derecho Internacional impone a los Estados respecto de toda controversia cuya prolongación pueda poner en peligro la mantención de la paz y la seguridad, así como el deber de abstenerse de realizar acciones que puedan tener esas consecuencias. El Cap. I de la Declaración de Manila expone estos conceptos.

Una referencia específica a este punto contiene el Tratado de Paz y Amistad de 1984, entre Argentina y Chile, cuyo Art. $3^{\circ}$ dispone que "Si surgiere una controversia, las Partes adoptarán las medidas adecuadas para mantener las mejores condiciones generalès de convivencia en todos los ámbitos de sus relaciones y para evitar que la controversia se agrave o se prolongue".

La obligación básica del Derecho Internacional consuetudinario se caracteriza por ser una obligación de comportamiento, es decir la de procurar la búsqueda de una solución por medios pacificos cuya primera etapa es la negociación. En el Asunto de la Plataforma Continental del Mar del Norte (I.C.J. Reports 1969, p. 48) la C.J.I. señaló que las partes tenían el deber de comportarse de tal manera que la negociación tuviera un sentido, lo cual no ocurre cuando una de ellas insiste en su propia posición sin que se observe ninguna modificación.

Se entiende, en consecuencia que la obligación de negociar no es puramente formal, sino que, dependiendo de las circunstancias e instrumentos juridicos aplicables, puede ser un procedimiento necesario para que sea posible la aplicación de un mecanismo con 
participación de terceros. La negociación puede ser además un requisito jurídico previo para que proceda el recurso ante un órgano arbitral o jurisdiccional ("Mrédable imridique"), condición que debe estar prevista en un tratado o convención que vincule a las partes en la controversia. A contrario sensu. este requisito no será exigible a falta de convenio, como lo ha sostenido la jurisprudencia (Asuntos de la Plataforma Continental del Mar Egeo, I.C.J. Reports 1978, p. 12 y de las Actividades Militares y Paramilitares en Nicaragua. I.C.J. Reports 1984, p. 440).

Si bien en el estado actual de la sociedad internacional, el Derecho Internacional no exige la utilización de mecanismos determinados, numerosas convenciones y tratados se celebran con ei fin de establecer mecanismos determinados, numerosas convenciones multi o bilaterales de solución, o incorporan cláusulas especiales para ese propósito. De estos instrumentos surgen auténticas obligaciones internacionales, como la expresara por ejemplo el Art. 37 (inc. $2^{\circ}$ ) de la Convención de 1907 para el Arreglo Pacífico de Conflictos Internacionales: "El convenio de arbitraje implica el compromiso de someterse de buena fe a la senten cia arbitral".

Una fórmula que consagra una obligación de carácter general es aquella redactada en los siguientes términos: "Las Altas Partes Contratantes se obligan a someter la jurisdicción de la Corte Internacional de Justicia todas las controversias de cualquier naturaleza que por cualquier causa surgicren entre ellas" (Art. I, Tratado General sobre Solución Judicial de Controversias entre Chile y Argenina, 1972. No-vigente).

\section{Eit principio de la libre cleceion de los medios}

De conformidad con el Art. 33 de la Carta de la ONU. 1. Las partes en una controversia cuya continuación sea susceptible de poner en peligro el mantenimiento de la paz y la seguridad internacional tratarán de buscarle solución, ante todo. mediante la negociación, la investigación, la mediación, la conciliación, el arbitraje. el arreglo judicial, el recurso a organismos o acuerdos regionales u otros medios pacíficos de su elección. Este corolario del Art. 2. 3 de la propia Carta. reconoce la libertad de selección de los medios que las partes en una controversia juzguen más apropiados. La 
Declaración de Manila, de 1982 (Res. 37/10) reconoce este principio y lo fundamenta en el de la igualdad soberana entre los Estados (Parte 1, 3). La Declaración precisa que el recurso o la aceptación de un procedimiento de solución libremente acordado por los Estados respecto de controversias existentes o futuras es compatible con el principio antes indicado.

Esta libertad de elección puede ser restringida o reglamentada mediante acuerdos generales de solución de controversias o por cláusulas relativas a procedimientos diplomáticos, arbitrales o judiciales que se incorporan en tratados y convenciones. La celebración de protocolos adicionales se ha utilizado asimismo en esta materia, a fin de permitir una opción a los Estados Partes de aceptar o rechazar anticipadamente mecanismos específicos para las controversias que surjan en relación con las disposiciones del acuerdo principal. Otra técnica, cuya aplicación es más reciente, es la inserción de cláusulas relativas a la solución pacífica, que no admiten reservas o sólo admiten determinadas reservas, dentro de un acuerdo de alcance general. Es el caso de la Parte XV de la Convención de las Naciones Unidas sobre el Derecho del Mar, de 1982, cuyo Art. 286 establece que "...toda controversia relativa a la interpretación o a la aplicación de esta Convención, cuando no haya sido resuelta por aplicación de la sección" 1 . se someterá, a petición, de cualcuiera de las partes en la controversia a la corte o tribunal que sea competente conforme lo dispuesto en esta sección". Las limitaciones y excepciones a este Articulo están expresamente previstas en la sección 3 de la Parte XV. El mismo alcance tiene el Tratado de Roma, de 1957, al no admitir reservas a los mecanismos de solución de controversias que comprenden un órgano judicial comunitario.

En la práctica, dadas las características del orden internacional, los Estados recurren a una variedad de medios de solución, con una preferencia por los medios diplomáticos y políticos por sobre los jurisdiccionales. Puede ocurrir también que operen dos procedimientos de otra naturaleza. La C.I.J., en el Asunto de las Actividades Militares y Paramilitares en Nicaragua (Reports 1984 , p. 440) señaló que su actuación como tribunal no estaba subordinada al agotamiento de los procedimientos regionales de negociación. 
La C.I.J. en ese asunto, rechazó además el argumento de EE.UU. en el sentido de que un conflicto armado de naturaleza evolutiva no se prestaba a la aplicación del procedimiento judicial sino más bien procedía el recurso al Consejo de Seguridad, e indicó asimismo, que existían negociaciones pendientes entre ambas partes (IBID, p. 440). La C.J.I. proporciona varios ejemplos en los cuales se han seguido pari passu las negociaciones y el recurso al arreglo judicial (Asunto de la Plataforma Continental del Mar del Norte, I.C.J. Reports 1978 , p. 12) e incluso ha afirmado que un procedimiento judicial puede ser discontinuado si las negociaciones que se efectúan paralelamente tienen un resultado positivo (Asunto del Proceso a los prisioneros de guerra paquistaníes I.C.J. Reports 1973. p. 347).

La operación de estos principios jurídicos permite apreciar una función limitada de la solución judicial o arbitral de controversias, si bien ésta tiene un desarrollo importante en convenciones multilaterales recientes y en el marco de organizaciones internacionales regionales. Una demostración de las limitaciones a los procedimientos jurisdiccionales, se observa en la Convención de las Naciones Unidas sobre el Derecho del Mar, de 1982 que faculta a un Estado a exceptuar del arbitraje o solución judicial, las controversias relativas a actividades militares de buques y aeronaves de Estado, así como aquellas controversias respecto de las cuales el Consejo de Seguridad de la ONU, esté ejerciendo las funciones que le confiere la Carta (Art. 298. 1, b) y c)).

PARTE: II

\section{El Arbitraje}

\section{a) ANTECEDENTES:}

Es el medio jurisdiccional más antiguo, conocido desde la antigua Grecia. En la Edad Media y Renacimiento, el Papa y el Emperador fueron reconocidos como árbitros. En el Derecho Internacional Moderno, el Tratado Jay, de amistad. comercio y navegación entre Estados Unidos y el Reino Unido (1794) inicia un desarrollo fundamental de esta institución. Este tratado dio origen al arbitraje por Comisiones Mixtas compuestas por representantes de las partes en igual número. Funcionaron lasta 1831 . 
E1 Asunto del Alabama, entre Estados Unidos y el Reino Unido (1872), constituye un hito en la historia del arbitraje. EE.UU. acusaba al Reino Unido de haber transgredido sus deberes de neutral durante la llamada "guerra de secesión", permitiendo a los navíos de los insurrectos del sur, entre ellos el Alabama, equiparse y abastecerse en ese país. El Tratado de Washington, de 1871, que dio origen al arbitraje, en una innovación jurídica, fijó los principios jurídicos, en materia de reglas de neutralidad aplicables al caso.

El asunto fuc resuelto por un tribunal colegiado integrado por cinco miembros de los cuales cada parte designó dos y el quinto por un tercer Estado. Tres miembros poseían nacionalidad diferente que la de las partes. Esta modalidad resultó ser de interés para los Estados que hasta esa fecha optaban normalmente por constituir Comisiones Mixtas o por el arbitraje de un soberano (En 1874, el Institut de Droit International, inspirado en este auge, adoptó un Código sobre Procedimiento Arbitral y en 1875 , una Resolución sobre la materia).

La Conferencia de La Haya de 1899 adoptó una Convención sobre el Arreglo Pacífico de Controversias, cuyo título IV (Arts. 15 a 57) se dedicaron al arbitraje. En esta convención se desarrolla el concepto de justicia arbitral, se crea la Corte Permancnte de Arbitraje y se reglamenta el procedimiento arbitral.

La Convención de La Haya de 1907, para el Arreglo Pacífico de Controversias Internacionales, adoptada en la II Conferencia de la Paz, es una versión enmendada y perfeccionada del texto anterior. Después de 1919, la Asamblea de la Sociedad de las Naciones adoptó cl Acta General para el arreglo de los Conflictos Internacionales (1928), procedimiento que no desaparece de la práctica internacional a pesar de haberse creado en 1920 la Corte Permanente de Justicia Internacional. Esta Acta General fue revisada en 1949 por la Asamblea General de la ONU.

En la práctica bilateral, el arbitraje conoce un importante desarrollo. Un Tratado General de Arbitraje, de 1902, (Tratados, Convenciones y Arreglos Internacionales de Chile. 1810-1977. Tratados Bilaterales Chile-Argentina. Vol. I., Santiago, 1977, pp. 141-143. En adelante: Tratados Bilaterales Chile-Argentina) entre 
Argentina y Chile, dio origen a dos arbitrajes, fallados en 1966 y 1977 (Asuntos de la Frontera Chileno-Argentina y del Canal Beagle respectivamente). Ambos Estados vuelven a pactar cláusulas de arbitraje obligatorio en el Tratado de Paz y Amistad de 1984 (Art. 6 y Cap. II, Anexo $\left.N^{\circ} 1\right)$. En 1958, la Comisión de Derecho Internacional de la ONU adopta un "Modelo de Proyecto sobre Procedimiento Arbitral" (En adelante: "Reglas Modelo") cuyo propósito práctico ha sido el de servir de guía para los Estados. Este modelo perfecciona el procedimiento arbitral, haciéndolo más automático que de costumbre e incorporando recursos ante la Corte Internacional de Justicia.

\section{b) CONCEPTO}

La definición que goza de mayor aceptación es la que contiene el Art. 37 de la Convención de La Haya de 1907, en vi:tud del cual "El arbitraje internacional tiene por objeto arreglar los litigios entre los Estados por medio de jueces de su elección y sobre la base del respeto del derecho".

"El convenio de arbitraje implica el compromiso de someterse de buena fe a la sentencia arbitral". Los elementos fundamentales del arbitraje (de la esencia) son el acuerdo o consentimiento previo de las partes y la naturaleza decisoria y definitiva que posee la solución o sentencia que al árbitro adopta. El respeto al derecho que enuncia el Art. señalado no obsta a que se confieran al árbitro facultades para fallar ex aceuos et bono.

\section{c) RECURSO AI ARBITRAJE}

E1 carácter voluntario del arbitraje es la regla general. Una vez prestado el consentimiento por las partes, surge la irrevocabilidad de la promesa de recurrir al arbitraje o de la estipulación de recurrir a este procedimiento. No resulta en cambio este efecto de una disposición como la del Art. 38 de la Convención de La Haya de 1987 que dice: "En las cuestiones de orden jurídico, y en primer término, en la interpretación o aplicación de los convenios internacionales, las potencias signatarias reconocen el arbitraje como el medio más eficaz, y al mismo tiempo más equitativo, para el arreglo de los litigios que no han sido resueltos por la vía diplomática". El arbitraje es deseable, pero no obligatorio en este eje mplo. 
La jurisprudencia ha aplicado estos principios: "Está bien establecido en Derecho Internacional que ningún Estado puede considerarse obligado a someter sus diferencias con otros Estados, sea a la mediación, sea al arbitraje o a cualquier otro procedimiento de solución pacífica, sin su consentimiento. El consentimiento puede ser dado de una vez por todas, bajo la forma de una obligación libremente aceptada, o puede darse, por el contrario, en un caso determinado, fuera de toda obligación internacional" (Estatuto de Carelia Oriental. Serie B. $N^{\circ} 5$, p. 27).

Dos tipos de arbitraje pueden distinguirse teniendo en consideración las circunstancias - después del acuerdo- si antes o después de nacida una controversia y el grado de perfección del acuerdo que da lugar al arbitraje.

La sumisión al arbitraje puede efectuarse mediante un acuerdo internacional único (compromiso), concluido después que ha nacido un litigio o mediante una cláusula compromisoria incorporada en un tratado en el cual se establece la obligación de recurrir al arbitraje para resolver las controversias que surgieren respecto de la interpretación o aplicación del tratado, así como mediante un tratado general de arbitraje, que establezea el recurso al arbitraje sobre cualquier materia o para determinadas categorías de controversias. El primer caso se denomina Arbitraje lacultation; el segundo corresponde al Arbitraje Obligatorio.

Las Reglas Modelo de la Comisión de Derecho Internacional (1958) establecen en el Art. 1, 1) "Toda estipulación de recurrir al arbitraje para solucionar una controversia entre Estados constituye una obligación jurídica que ha de ser ejecutada de buena fe. 2) La obligación resulta del acuerdo de las partes y puede referirse a controversias (litigios) ya plateadas (arbitrajes ad hoc) o a controversias eventuales (Tratados de arbitraje, cláusulas compromisorias)".

Arbitraje facultatio... El consentimiento de las partes de someterse al arbitraje respecto de una controversia determinada se expresa mediante el compromiso. Siendo un tratado internacional, su validez se rige por los principios aplicables en el derecho de los tratados, se adopte bajo la forma de un tratado solemne o de un acuerdo en forma simplificada. 
El contenido del compromiso de arbitraje lo fijan libremente las partes; para la celebración de este compromiso pueden considerarse como reglas supletorias de la voluntad de las partes, las contenidas en convenciones multilaterales para el arreglo pacífico de las controversias, vigentes entre ellas, lo cual puede contribuir a resolver problemas técnicos que se planteen.

El compromiso debe contener, de acuerdo con las Reglas Modelo de la C.D.I. (1958): a) La estipulación de arbitraje en virtud de la cual se someterá la controversia a los árbitros; b) El objeto de la controversia y, de ser posible, los puntos sobre los cuales las partes estén de acuerdo o en desacuerdo: c) El modo de constituir el tribunal y el número de árbitros.

A título puramente enunciativo, las Reglas Modelo de la C.D.I. indican que el compromiso podrá contener. entre otros elementos: 1) Las reglas de derecho y los principios que deberá aplicar el tribunal y la facultad que en su caso se le confiera de decidir ex acyuo et bono, como si tuviese facultades legislativas en la materia; 2) La facultad de hacer recomendaciones a las partes; 3) La facultad que se reconozca al tribunal de fijar sus propias normas de procedimientos; 4) El procedimiento que ha de seguir el tribunal, a condición de que, una vez constituido, quede facultado para desechar las disposiciones del compromiso que puedan impedirle dictar sentencia, ctc.

A su vez, el Art. 52 del Convenio de La Haya de 1907 señala "Las Potencias que recurran al arbitraje firmarán un compromiso en el que se determine el objeto del litigio, el plazo para el nombramiento de árbitros, la forma, el orden y los plazos en que deberá hacerse la comunicación a que se refiere el Art. 43 -se refiere a la Corte Permanente de Arbitraje- y el importe de la suma que cada una de las partes deberá depositar como adelanto para los gastos".

Si procede, el compromiso determinará también el modo de hacer el nombramiento de los árbitros, los poderes eventuales del tribunal, su residencia, el idioma que usará y aquellos cuyo empleo ante él se autoriza, y en general todas las condiciones convenidas por las partes". Por cjemplo, para la Delimitación de la Plataforma Continental entre Francia y el Reino Unido (1977), las partes cele- 
braron su Acuerdo de Arbitraje en 1975 (International Legal Materials, XVIII, 1979, 2, pp. 400-401), una de cuyas disposiciones señala el objeto de la controversia y el derecho aplicable: "Article 2. 1. The Court is requested to decide, in accordance with the rules of international law applicable in the matter as between the Parties, the following question:

What is the course of the boundary (or boundaries) between the portions of the continental shelf appertaining to the United Kingdom and the Channel Islands and to the French Republic, respectively, west ward of 30 minutes west of the Greenwich Meridian as far as the 1000 metre isobath?

2.- Choise of the 1.000 metre isobath is without prejudice to the position of either Government concerning the outer limit of the continental shelf".

En el compromiso puede conferirse jurisdicción sólo para decidir sobre determinados puntos de derecho o de hecho o en él una parte puede admitir su responsabilidad y se solicita, por lo tanto, al tribunal que determine el monto de la indemnización. Las disposiciones del compromiso relativas al derecho aplicable. son esenciales para interpretar la sentencia y determinar su valor como precedente.

En relación con las normas de procedimiento que no quedan resueltas en el compromiso, éste confiere normalmente al tribunal el poder para llevar a cabo su tarea de manera que no vulnere la estipulación del arbitraje.

Arbitraje Obligatorio. - Si en virtud de un tratado general de arbitraje o por cláusula compromisoria, cualquiera de las partes puede someter una controversia a este procedimiento, el arbitraje es obligatorio. En la práctica puede suceder que aunque exista un acuerdo obligatorio, se requiera la celebración de un compromiso para precisar el objeto de la demanda, así como el procedimiento.

Por ejemplo en los asuntos suscitados entre Chile y Argentina durante la vigencia del Tratado General de Arbitraje de 1902, el Asunto de la Frontera Chileno-Argentina o del Río Encuentro (1966) y el del Canal Beagle (1977), se suscribió un compromiso 
especial. En el primer caso, el ministro de Relaciones Exteriores del Reino Unido suscribió, en nombre del gobierno británico, el "Acuerdo Compromisorio para arbitrar una Controversia entre la República Argentina y la República de Chile, fijado por el Gobierno del Reino Unido de Gran Bretaña e Irlanda del Norte" (1965. Tratados Bilaterales Chile-Argentina, Vol. 2. Santiago, 1977, pp. 743-746). En el segundo caso, el compromiso o acuerdo de arbitraje fue suscrito por las partes (1971), con artículos que pueden considerarse típicos de un compromiso arbitral. Se observa en este caso que cada parte formuló una pregunta independiente al árbitro (Art. 1).

Sin embargo, el Tratado de 1902 entre ambos países contenia además una cláusula (Art. V) en virtud de la cual "En defecto de acuerdo, cualquiera de las partes podrá solicitar la intervención del árbitro, a quien corresponderá fijar el compromiso, la época, lugar $\mathrm{y}$ formalidades del procedimiento, así como resolver todas las dificultades procesales que pudieran surgir en el curso del debate. Los compromitentes se obligan a poner a disposición del árbitro todos los medios de información que de ellos dependan".

La cláusula compromisoria. - Se incorpora en tratados cuyo propósito u objeto es otro que la solución de las controversias. Es una cláusula frecuente en las convenciones multilaterales (Sohn, L. "Settlement of Disputes Relating to the Interpretation and Application of Treaties" Recueil des Cours, 1976, 11, pp. 244-279). Por ejemplo el Convenio sobre la Responsabilidad Internacional por daños causados por objetos espaciales, 1971, establece que "si no se logra resolver una reclamación mediante negociaciones diplomáticas,....., las partes interesadas, a instancia de cualquiera de ellas, constituirán una Comisión de Reclamaciones". (Art. XIV). La decisión de la Comisión será firme y obligatoria si las partes así lo han convenido. Una cláusula especial contiene la Convención de Chicago de 1944 sobre la Aviación Civil Internacional acerca de la facultad del Consejo de OACI de decidir a petición de cualquier Estado en una controversia (1.5 U.N.T.S., p. 295, Art. 84). A nivel bilateral, puede mencionarse el Tratado Chileno-Peruano de 1929. cuyo artículo duodécimo dispone "Para el-caso en que los gobiernos de Chile y Perú no estuviesen de acuerdo en la interpretación que den a cada una de las diferentes disposiciones de este Tratado, y en que. a pesar de su buena voluntas. no pudieren 
ponerse de acuerdo, decidirá el presidente de los Estados Unidos de América la controversia". Un tipo de cláusula que establece una obligación de someterse a un procedimiento de solución, cl cual se originará mediante otro acuerdo ulterior que perfecciona la obligación es el siguiente: "Article VII. 1. Disputes arising out of the application or interpretation of this Treaty shall be resolved by negotiations. 2. Any such disputes which cannot be settled by negotiations shall be resolved by conciliation or submitted to arbitration" (Tratado de Paz entre Egipto e Israel, 26-III-1979. I.L.M., XVIII, 1979, 2, p. 336).

La cláusula compromisoria es especial si es aplicable a cualquier controversia que surja del Tratado que la contiene. Será general si se aplica a controversias que puedan nacer fuera del Tratado.

En los tratados relativos a protección de inversiones suele incorporarse una cláusula compromisoria para la solución de las controversias entre Estados. Por ej. el Tratado entre Panamá y Estados Unidos, de 1982, relativo al Trato y Protección de las Inversiones (I.L.M. XXI, 1982, 6, pp. 1227-1244) estipuló que "'2. If the disputes between the Partics cannot be resolved through the aforesead means, and unless there is agreement between the Parties hereby agree to submit it upon the request of either Party to an arbitral tribunal for binding decision in accordance with the applicable rules and principles of international law" (Art. VIII, 2).

Tratado General de Arbitraje es aquel cuyo objeto principal es el establecimiento del recurso al arbitraje, como mecanismo principal o junto a otros métodos de solución de controversias, especialmente con el de conciliación. Hasta 1914, la mayoría de estos tratados se concluyen bilateralmente (139 convenciones, entre 47 Estados (El más destacado es el franco-británico de 1903) (Nguyen Quoc Dinh, Droit International Public, 3a. éd. Paris, L.G.D.J. 1987, p. 759).

El Acta General de 1928 es el instrumento más importante del periodo de la Sociedad de las Naciones; fue revisada en 1949 por la Asamblea General. Las Reglas Modelo adoptadas por la Comisión de Derecho Internacional en 1958 no poseen naturaleza obligatoria. Estos instrumentos, obligator ios o recomendados, han 
sido constantemente sometidos a la crítica de quienes - Estados y doctrina - apoyan un desarrollo más vigoroso de la jurisdicción de tribunales permanentes.

Como lo fue el Tratado de 1902 General de Arbitraje, el Tratado de Paz y Amistad de 1984 (Diario Oficial, Chile, 14-V-1985. pp. 3-6), entre Argentina y Chile puede ser calificado como un Tratado general de arbitraje en lo que respecta a sus Arts. 6 y Cap. II, del Anexo N" 1 titulado "Procedimiento Arbitral previsto en el Artículo $6^{\circ}$ del Tratado de Paz y Amistad". Por el Art. $6^{\circ}$, inc. $1{ }^{\circ}$, "Si ambas Partes o una de ellas no hubieren aceptado los términos de arreglo propuestos por la Comisión de Conciliación dentro del plazo fijado por su Presidente, o si el procedimiento de conciliación fracasare por cualquier causa, ambas Partes o cualquiera de ellas podrá someter la Controversia al procedimiento arbitral establecido en el Capítulo II del Anexo $N^{\circ} 1$ ". El recurso al arbitraje no se limita exclusivamente a las controversias que se refieren a las materias contenidas en el tratado. En el Sistema Interamericano, los acuerdos generales de arbitraje más relevantes han sido el Tratado General de Arbitraje Interamericano y Protocolo Adicional de Arbitraje Progresivo, de 1929 y el Pacto de Bogotá, de 1948, que sustituye al anterior entre las partes.

\section{d) LA "ARBITRABILIDAD”}

En esta matcria se reiteran los conceptos expuestos en la I PARTE, acerca de la distinción entre controversias jurídicas y controversias políticas. Puede constatarse asimismo que ciertas convenciones conciben el arbitraje como un procedimiento apropiado para resolver litigios diferentes que los que se someten a la jurisdicción de la Corte Internacional de Justicia, para quien se reservan las controversias denominadas jurídicas. Por ejemplo, el Pacto de Bogotá (1948), vigente para 13 Estados americanos y la Convención Europea para la Solución Pacífica de las Controversias (1957).

Por otra parte, los Estados pueden definir qué se entenderá por controversias arbitrales con el objeto de poner en acción una convención que prevé este mecanismo. Los Pactos de Locarno de 1925 y el Actal General de 1928 definían la arbitrabilidad como acpuellas controversias en las cuales las partes se discuten recíprocamente un derecho. Otro modelo que se ha seguido es el de reto- 
mar las categorías de controversias jurídicas que describe el Estatuto de la Corte Internacional de Justicia, en su Art. 36, inc. $2^{\circ}$. a. la interpretación de un tratado; $b$. cualquier cuestión de derecho internacional; c. la existencia de todo hecho que, si fuere establecido, constituiría violación de una obligación internacional; d. la naturaleza o extensión de la reparación que ha de hacerse por el quebrantamiento de una obligación internacional.

Una proposición original en favor de la arbitrabilidad de ciertas controversias ofreció un proyecto suizo presentado en 1973 originalmente, y revisado en 1978, en el seno de la Conferencia para la Seguridad y la Cooperación en Europa. De acuerdo a éste, eran arbitrables las controversias relativas a la responsabilidad internacional y la protección diplomática; asuntos de vecindad (fronteras, servidumbres internacionales, reglamentación de vías fluviales internacionales, relaciones de vecindad); el derecho de los transportes ferroviarios, ruteros y aéreos; medio ambiente; derecho diplomático y consular; derecho penal; validez, entrada en vigor y extinción de los tratados $y$, finalmente, la interpretación o la aplicación de convenciones que no fuesen tratados de alianza (Caflisch, L. "L'Avenir de l'Arbitraje Interétatique": A.F.D.I. 1979, pp. 33-34).

En general, la cláusula de arbitrabilidad pucde ir acompañada de reservas previstas en el propio tratado general o en la cláusula compromisoria. Una de estas reservas que se entiende implícita en todo acuerdo de arbitraje, deriva de un principio general del derecho según el cual no pueden renovarse en virtud de un recurso arbitral las cuestiones que hubieran sido objeto de arreglos definitivos entre las partes. Un nuevo arbitraje sólo podría suscitarse en relación con la validez, interpretación y cumplimiento de dicho arreglo (Es el sentido del Art. VI del Pacto de Bogotá de 1948).

Cuando el tratado general o la cláusula compromisoria no son suficientes para que se active el procedimiento arbitral, es preciso celebrar un compromiso, que haga efectiva la obligación de principio de recurrir al arbitraje, incluyendo la precisión del objeto de la controversia. Puede ocurrir en determinadas circunstancias que la "arbitrabilidad" sea rehusada por una de las partes como justificación para negarse a cooperar en la constitución del órgano arbitral. 
Por ejemplo, en la designación de un árbitro o del superárbitro. Un eventual conflicto sobre la "arbitrabilidad" de una controversia puede ser sometido a otra instancia jurisdiccional que haya sido aceptada por las partes. Es el caso del Asunto Ambatielos entre Grecia y el Reino Unido.

En este asunto, Grecia ejerciendo la protección diplomática a nombre de uno de sus nacionales que no había logrado obtener satisfacción en una controversia contractual con el Reino Unido, requería que se procediera al arbitraje de acuerdo con una cláusula compromisoria especial contenida en una declaración anexa a un tratado de 1926 que preveía el arbitraje para las reclamaciones fundadas en un tratado de 1886. El Reino Unido rechazaba la procedencia de este mecanismo, aduciendo que no se trataba de una controversia relativa a la interpretación y a la aplicación de ese tratado. Grecia planteó la controversia acerca de la arbitrabilidad a la C.I.J., quien se declaró competente (I.C.J. Reports 1952, p. 28) y decidió que la controversia estaba sometida a la obligación de arbitraje (Reports 1953, p. 10). Pudo constituirse así, el órgano arbitral encargado de decidir el fondo del asunto.

\section{El Organo Arbitral}

La diferencia esencial entre el arbitraje y la solución judicial reside en el método de selección de los miembros de estos órganos judiciales. En un procedimiento arbitral, aquél se realiza mediante aeuerdo entre las partes, la solución judicial presupone la existencia de un tribunal permanente, con sus propios jueces y reglas do procedimiento que deben ser aceptadas por las partes (Sshwarzenberger, G. Manual of Intemational Law, 6th ed., 1976, p. 195).

El órgano arbitral se constituye por acuerdo de las partes de conformidad con el principio consuetudinario que les reconoce el derecho a crear el tribunal. El carácter ocasional de este órgano es el principio básico, a pesar de que existen intentos de institucionalización (Nguyen Quic Dinh, Loc. cit. p. 762). Por ejemplo, los Arts. 55 de la Convención Europea, 1957 y 4 de las Reglas Modelo de la C.D.I., 1958.

En el acuerdo de arbitraje (tratado general, cláusula compromisoria) puede preverse la intervención de un tercero que impida 
la paralización del mecanismo a causa de que una de las partes rehuse su consentimiento a la designación de un miembro del tribunal o del tribunal mismo si es unipersonal. Este tercero puede ser designado en el Presidente de la Corte Internacional de Justicia, el Secretario General de la ONU u otra autoridad. Las Reglas Modelo de la C.D.I., 1958 indican que "Art. 4.

2. Si el tribunal no se hubiere constituido dentro de los tres meses siguientes a la fecha de petición de que se someta la controversia al arbitraje o de la decisión sobre la arbitrabilidad, el Presidente de la Corte Internacional de Justicia, a petición de cualquiera de las partes, nombrará a los árbitros aún no designados. Si el Presidente de la Corte Internacional de Justicia no puede actuar o si es nacional de una de las partes, hará los nombramientos el vicepresidente. Si éste no puede actuar o si es nacional de una de las partes, hará los nombramientos el miembro de más edad de la Corteque no sea nacional de ninguna de las partes".

El Tratado de Paz y Amistad entre Argentina y Chile, 1984, encomienda la designación de los mie mbros del tribunal arbitral, a falta de acuerdo entre las partes, al Gobierno de la Confederación Suiza a solicitud de cualquiera de las partes (Art. 25. Anexo No 1 ).

En el Asunto de la Interpretación de los Tratados de Paz con Bulgaria, Hungría y Rumania, la C.I.J. emitió una Opinión Consultiva (Reports 1950, p. 221) en la cual constató que el Secretario General no podía designar al tereer miembro del tribunal si una de las partes rehusaba colaborar designando al micmbro nacional del arbitraje. El arbitraje previsto en esos Tratados de Paz, no pudo concretarse.

\section{a) Estructura del Organo Arbitral}

El Arbitro Unico; ha sido la fórmula antigua generalizada. en especial por el arbitraje de jefe de Estado o soberano. Paulatinamente ese arbitraje se ha ido sustituyendo por el de juristas connotados, magistrados, diplomáticos, etc. Un ejemplo del primer caso es el arbitraje del Asunto Clipperton. entre Francia y México resuelto en 1931 por el Rey de Italia (A.J.I.L., 1931, pp. 390 y ss). 
Il Tratado General de Arbitraje de 1902, entre Chile y Argentina, designaba como árbitro al Gobierno de Su Majestad Británica. Sin embargo, para el Asunto del Canal Beagle, el compromiso estableció una Corte Arbitral compuesta de 5 miembros jueces de la C.I.J., la cual emitiría una decisión que podía ser rechazada o aceptada por el árbitro (Ver Supra II Parte, 1, c).

Comisión Mixta. El Tratado Jay de 1794 entre EE.UU. y el Reino Unido implantó esta modalidad. Originalmente. la Comisión Mixta fue paritaria, integrada por miembros designados por cada parte, en igual número y de su nacionalidad. Un tercer miembro, de otra nacionalidad se incorpora más tarde a estas comisiones en calidad de "super árbitro" (umpire), participando en la deliberación en caso de desacuerdo entre los miembros o comisarios nacionales.

Una modalidad más evolucionada del arbitraje por Comisión Mixta es aquella que hace participar al super árbitro en calidad de presidente, y que incluso incorpora comisarios o miembros que no son de la nacionalidad de las partes. Han sido los casos de las Comisiones de 1903 entre Venezuela y los Estados curopeos (Italia, Reino Unido, Alemania); las comisiones establecidas en 1922 y 1927 entre México y Francia; México y Reino Unido (Nguyen Quoc Dinh, Loc. cit. pp. 762-763).

Tribunal Colegiado. Es la modalidad más actual, que permite integrar el órgano arbitral por 3 ó 5 miembros, con una participación de miembros neutrales. La Convención de Washington de 1871 (Asunto Alabama) entre EE.UU. y el Reino Unido, estableció por primera vez una estructura colegiada de este tipo, presidida por un neutral. Fue utilizada asimismo para la constitución de los Tribunales Arbitrales Mixtos creados en 1919 en virtud de los Tratados de Paz y cuya competencia se extendió a las controversias relativas a las medidas adoptadas durante la guerra por los gobiernos enemigos contra los bienes de nacionales de Estados vencedores. En virtud de los Tratados de Paz de 1947, se crearon comisiones de conciliación que funcionaron según principios similares y constituyeron en la práctica verdaderos tribunales. En el Tratado de Paz y Amistad entre Argentina y Chile, el Tribunal Arbitral se compone de 5 miembros, salvo acuerdo en contrario (Art. $24^{\circ}$ Anexo $\left.\mathrm{N}^{\circ} 1\right)$. Cada una de las partes, nombra un miembro y los 
otros tres serán nombrados de común acuerdo entre nacionales de terceros Estados.

\section{b) Competencia del Organo Arbitral}

Las competencias del Organo Arbitral derivan del compromiso de arbitraje. Debido a su naturaleza jurisdiccional, el órgano interpreta ese compromiso. Es lo que se denomina "competencia de la competencia", pudiendo en virtud de ésta, resolver toda contestación entre las partes acerca del alcance de los poderes del árbitro. El Art. 10 de las Reglas Modelo de la C.D.I., 1958, señala que:

"El tribunal arbitral, juez de su propia competencia, dispone de las más amplias facultades para interpretar cl compromiso".

Estas reglas reconocen al Organo Arbitral que estuviere constituido (Art. 9) la competencia para decidir si existe entre las partes un acuerdo suficiente respecto de los elementos esenciales de la controversia fijados en el Art. 2 (compromiso) que le permita examinar la cuestión. Estos elementos pueden estar contenidos en la estipulación de arbitraje o en cualquier acuerdo complementario cuyas disposiciones parezcan suficientes para servir de compromiso.

La Determinación del Derecho Aplicable. El tribunal estatuye o decide sobre la base del derecho, a menos que las partes le indiquen lo contrario. El compromiso remite al tribunal a "principios de Derecho Internacional", "Derecho Internacional" (figura por primera vez en los tratados concluidos por Chile con otros Estados (1982) para la reparación de daños ocasionados a nacionales extranjeros en el marco de la guerra de 1879), "principios generales del Derecho", o reitera la enumeración del Art. 38 del Estatuto de la Corte Internacional de Justicia (Reglas Modelo de la C.D.I., 1958, Art. 11).

El compromiso puede también señalar como derecho aplicable, determinadas reglas especiales respecto de las cuales existe acuerdo entre las partes. Por ejemplo el Tratado de Washington de 1871 entre EE.UU. y el Reino Unido estableció reglas especiales 
de neutralidad conforme a las cuales se resolver ía sobre la responsabilidad británica (Asunto de Alabama). Igual propósito tuvo el compromiso entre EE.UU. y Canadá por el Asunto de la Trail Smelter, 1935 (R.S.A. Vol. III, p. 1907).

Competencias Especiales. Estas competencias pueden conferirse:

I) Bajo la fórmula de que el tribunal decida o busque una solución transaccional, sobre la base de consideraciones no-jurídicas. En la práctica, el árbitro actúa como un amigable componedor o ejerce una función de conciliación obligatoria; se menciona como ejemplo los Asuntos de la Isla de Bulama, 1870 (R.S.A. Vol. II, p. 612) y de la Bahía de Delagoa, 1875 (R.S.A. Vol. III, p. 637); Asunto de la Guyana, 1891, Francia y Reino Unido (La Fontaine, Pasicrisie Internationale, 1902. p. 329).

II) Utilizando la fórmula de que el árbitro resuclva $E x$ ac(fuo e' $t$ bono. Así lo admite el Acta General de Arbitraje de 1928, en el Art. 28, en caso de laguna jurídica.

III) En ciertos casos, el compromiso puede conferir competencia al árbitro para que proceda a un "arreglo de intereses". Ha ocurrido en los Asuntos de las Focas del Mar de Behring, 1893 (Clunet 1893, p. 1259); en las Pesquerías del Atlántico, 1910 (R.S.A. Vol. XI, p. 173) y en el Trail Smelter, 1938 (R.S.A. Vol. III, p. 1911).

La Institucionalización del Arbitraje. La doctrina define como institucionalización de hecho, el fenómeno de estipulaciones de arbitraje para una serie de controversias ya nacidas, vinculadas entre sí o similares. Ha sido el caso de las comisiones mixtas de conciliación posteriores a la guerra y es el caso del tribunal creado por el Acuerdo de Argelia entre Irán y EE.UU. 198 (I.L.M. XX, 1981, 1, pp. 223-233). La institucionalización jurídica derivaría de la estipulación que garantiza el recurso unilateral al arbitraje, de manera que una parte renuente a aceptarlo no podría entorpecerlo negándose a celebrar el compromiso.

El intento más trascendente de establecer un tribunal arbi- 
tral se realizó con la Convención de La Haya, 1899, sobre la Solución de Controversias, que creó la Corte Permanente de Arbitraje (C.P.A.). Su reglamentación fue revisada en la I Convención de La Haya de 1907. Aunque su nombre indica que se trata de un tribunal permanente, es sólo una lista de árbitros constituida por listas "nacionales" de árbitros designados por los Estados Partes en las Convenciones de La Haya. La permanencia está dada por la secretaría de la sede en el Palacio de la Paz de La Haya. Sus características son las siguientes:

I) Su objetivo es facilitar el recurso inmediato al arbitraje (Art. 41); II) Su sede es La Haya donde radica la Oficina Internacional que sirve de secretaría: ésta transmite todas las comunicaciones relativas a reuniones, custodia los archivos y gestiona los asuntos administrativos (Art. 43): III) Los "Miembros de la Corte" pertenecen a una lista de árbitros formada de la siguiente manera: "Cada una de las potencias signatarias nombrará cuatro personas, como máximo, de reconocida competencia en cuestiones de Derecho Internacional, que gocen de la más alta consideración moral y se hallen dispuestas a aceptar las funciones de árbitro (Art. 44). Estas personas son nombradas por seis años y sus poderes son renovables; IV) Para constituir el Tribunal cada parte nombra los árbitros, uno de los cuales puede ser de su nacionalidad. Los 4 miembros eligen de común acuerdo un superárbitro. Si no hay acuerdo, esta designación se confía a una tercera potencia, y si tampoco se llega a un acuerdo, se designan dos Estados para que efectúen esa designación. Si no hubiere acuerdo en esta ctapa, cada parte designa dos candidatos para que por sorteo se designe el superárbitro (Art. 45) (M. Diez de Velasco. Instituciones de Derecho Internacional Público. 6a. ed. T.I. Madrid, Tecnos, 1983, Cap. XL: Francois, J.P.A. "La Cour Permanente d'Arbitrage, son origine. Sa jurisprudence, son avenir" Recueil des Cours, 87, 1957, I, pp. 457-553).

Los asuntos juzgados por la C.P.A. son poco numerosos, 20 en total, siendo 1932 la fecha de la última sentencia. En 1962, la oficina de la C.P.A. adoptó un "reglamento de arbitraje" para asuntos en los cuales sólo una de las partes es un Estado. No ha sido exitoso (G. Guyomar, A.F.D.I. 1962, pp. 377-390). 


\section{Procedimiento Arbitral}

El procedimiento es acordado por las partes en el compromiso o en el acuerdo general de arbitraje que las vincula. En la práctica, se consideran textos supletorios las reglas establecidas en tratados generales como las Convenciones de La Haya de 1899 y 1907 y el Acta General de 1928, revisada en 1949. Los principios consuetudinarios aplicables en la materia facultan al órgano arbitral a precisar las reglas de procedimiento, a falta de reglas expresas.

Las reglas supletorias indicadas o las Reglas Modelo de la C.D.I., 1958, buscan aplicar técnicas semejantes a las utilizadas en una jurisdicción permanente.

Hasta las Convenciones de La Haya de 1899 y 1907, el procedimiento era conducido sobre una base más inquisitiva que contradictoria. Es así como no se conocía una parte demandante y otra demandada, stricto sensu.

A partir de esas convenciones, se organiza un verdadero proceso, las partes designan sus agentes. consejeros y abogados; se distinguen las fases escritas: presentación de Memoria. Contramemoria, Réplica y Dúplica y de piezas o documentos invocados en la causa, y oral o vista: alegatos en los que se exponen las razones de las partes.

Conforme a las normas de La Haya, las partes tienen derecho a promover excepciones e incidentes procesales. Los miembros del tribunal pueden dirigir preguntas a los agentes o consejeros y pedirles esclarecimientos acerea de puntos dudosos. El presidente del tribunal declara concluidos los debates una vez presentadas las aclaraciones y pruebas por los consejeros y agentes. Las deliberaciones del tribunal serán secretas. Las decisiones se adoptan por mayoría, la sentencia debe ser motivada, leída en sesión pública y decidirá el asunto definitivamente y sin apelación. La interpretación y la ejecución de la sentencia se someterá al juicio del órgano arbitral que la dictó. La sentencia arbitral es obligatoria sólo para las partes en litigio. 
Existen particularidades en la instancia arbitral que merecen destacarse: la práctica de las opiniones disidentes de los jueces minoritarios atenúa en la práctica el secreto absoluto de las deliberaciones del tribunal. Asimismo, para la prueba ante los órganos arbitrales es usual recurrir a la técnica anglo-sajona del estoppel, en cuanto excepción perentoria que se opone respecto.de una parte que pretende adoptar una posición contradictoria con lo que ha admitido anteriormente (Guggenheim. Traité de Droit International Public, T. Il, p. 158).

\section{La Sentencia Arbitral}

La decisión final del órgano arbitral cierra la instancia. Por regla general, su pronunciamiento requiere de la mayoría de los niembros.

a) Obligación de Motivar la Sentencia: deriva de las reglas de La Haya, 1907. Era poco frecuente en los arbitrajes por soberano o jefe de Estado. El compromiso señala generalmente que existe esta obligación. Las Reglas Modelo de la C.D.I., 1958, señalan que "La sentencia arbitral deberá ser motivada sobre todos los puntos que decida" (Art. 31 ).

b) Naturaleza obligatoria de la sentencia: dada su naturaleza de acto jurisdiccional, la sentencia arbitral está dotada de autoridad de cosa juzgada. La sentencia, por lo tanto, decide definitivamente la controversia y como lo indican las Reglas Modelo de la C.D.I. "es obligatoria para las partes desde el momento en que sea dictada. Deberá ser ejecutada de buena fe inmediatamente, a menos que el tribunal haya fijado plazos para su ejecución total o parcial" (Art. 32). Esta obligatoriedad es de alcance relativo, impone el deber de adoptar las medidas jurídicas y de hecho que se requieran, administrativas, legislativas $u$ otras.

c) Ejecutoriedad de la Sentencia (Bowett, "Contemporary Developments in Legal Techniques in the Settlement of Disputes". Recueil des Cours, 180, 1983, III, pp. 169-236). Es uno de los aspectos más controvertidos de la sentencia arbitral. La imposibilidad de ejecución forzosa por un órgano internacional no implica que la sentencia carezca de obligatoriedad y su ejecución integral 110 está protegida por la buena fe de las partes. Un rechazo de la 
sentencia arbitral, que se acompane de un rechazo a interponar los recursos procesales, hará surgir la responsabilidad internacional.

La carta de la ONU no contiene disposiciones en la materia, a diferencia del Pacto de la Sociedad de las Naciones que preveía en su Art. 13,4) que el consejo adoptara medidas para asegurar la ejecución. Los tratados generales de arbitraje pueden contener disposiciones que permitan recurrir al tribunal que dictó la sentencia para resolver toda controversia relativa a su ejecución. Para estos efectos, el tribunal arbitral no debe haber cesado de funcionar.

Un caso de rechazo a aceptar una sentencia se produjo en el Asunto del Canal Beagle, entre Argentina y Chile (1977). Argentina invocó una serie de supuestos vicios que a su juicio invalidaban la sentencia arbitral (1978, I.L.M. XVII, 1978, 3, pp. 738-750). El tribunal protestó respecto de esta actitud (R.G.D.I.P. 1978, p. 636). Posteriormente, la sentencia fue confirmada por el Tratado de Paz y Amistad entre ambos Estados, 1984.

d) Recursos. Si bien la sentencia es definitiva, se admite la presentación de recursos. Este derecho se ejerce dentro de los márgenes que admite el carácter no-permanente que posee el órgano arbitral.

Recurso de Interpretación. "Ejus est interpretari cujus est condere". Se. interpone ante el tribunal que dictó la sentencia (Art. 82 de la Convención de La Haya de 1907 y Art. 60 del Estatuto de la C.I.J. y 70 de su Reglamento). Las Reglas Modelo de la C.D.I., 1958, consagran expresamente este recurso (Art. 35) y proponen que se someta este recurso a la C.I.J. en caso de que por cualquier razón, resulta imposible someter la controversia al tribunal que hubiese dictado la sentencia y si las partes no han acordado otra solución dentro del plazo de tres meses. En la práctica, el mismo tribunal conoció y resolvió el recurso de interpretación interpuesto contra la sentencia en el Asunto de la Plataforma Continental entre el Reino Unido y Francia (1978, I.L.M., XVIII, 1979, 2, 462-494).

Recurso de Revisión. Procede si una parte invoca un "hecho nuevo" de tal naturaleza que pueda tener una influencia decisiva sobre la sentencia, a condición de que este hecho hubiera sido des- 
conocido para el tribunal y para la parte que pida la revisión y de que esa ignorancia no se deba a negligencia de dicha parte (Art. 39. Reglas Modelo de la C.D.I.. 1958 y Art. 83 de la Convención de La Haya de 1907).

Debido a la trascendencia de una eventual revisión, los tratados generales o los compromisos establecen limites en el tiempo, tanto respecto de la fecha de dictación de la sentencia, como de conocido el hecho nuevo. para que proceda interponer este recurso. Este elemento temporal implica el deber del tribunal de examinar la admisibilidad del recurso antes de decidir el fondo.

E1 Art. 40. Anexo $N^{\circ} 1$ del Tratado de Paz y Amistad entre Argentina y Chile acepta el recurso de revisión por otras hipótesis:

"Cualquiera de las partes podrá pedir la revisión de la sentencja ante el tribunal que la dietó siempre que se deduzea antes de vencido el plazo señalado para su ejecución, y en los casos siguientes: 1. - Si se ha dictado sentencia en virtud de un documento falso o adulterado. 2.- Si la sentencia ha sido en todo o en parte consecuencia de un error de hecho, que resulte de las actuaciones o documentos de la causi" $"$.

Estas causales fundamental lo que la doctrina denomina generalmente recurso de reforma.

Recurso de Reforma. Nommalmente referido al recurso destinado a obtener una declaración de nulidad de la sentencia arbitral. Aunque es un tema polémico en doctrina y en la práctica. se reconocen dos causas principales de nulidad: la malidad del compremiso arbitral, gue sirve de fundamento de la sentencia y el exceso de poder del arbitro. Las Reglas Modelo de la C.D.I. 1958. aceptan las siguientes causas: "a) Exceso de poder del tribunal; b) Corrupción de un miembro del tribunal; c) Infraceión grave de una norma fundamental de procedimiento. incluso el hecho de que la sentencia no exprese. total o parcialmente. los motivos en que se funda". En el Asunto del Chamizal entre EE.UU. y México (1911), fallado por una Comisión Arbitral. EE.UU. impugnó la validez de la decisión basándose en exeeso de poder y desviación de los términos del compromiso (International Boundary Commission, pp. 56-57. 
Foreign Relations of the U.S., 1911, p). 597-598). En 1963 ambos Estados concluycron un acuerdo que puso término definitivamente a la controversia (505 U.N.T.S. 185). A su vez. Venezuela sostiene que el Laudo Arbitral de 1899 sobre los límites de Venezuela con la Guayana Británica es nulo, basándose entre otras consideraciones en el exceso de poder del árbitro, carencia de motivación de la sentencia, alteración de mapas y documentos y un presunto acuerdo ruso-británico para favorecerse recíprocamente en sus intereses territoriales. (Gros Espiell, H. "Estudio Preliminar" en F. Martens Rusia e Inglaterra en Asia Central. Caracas, Ed. Presidencia de la República, 1981, pp. 42-46).

E1 Derecho Internacional busca evitar que una de las partes invoque la nulidad como causa para declarar unilateralmente la inejecutabilidad de la sentencia. Para evitar esto, se prevé la interposición de recursos ante el mismo tribunal que dictó la sentencia (Tratado de Paz y Amistad entre Argentina y Chile, 1984) o se recomienda la interposición del recurso ante otro tribunal competente (Reglas Modelo de la C.D.I., 1958).

En la práctica, se conocen casos sometidos a una segunda instancia por acuerdo entre las partes. Así por ejemplo. Honduras y Nicaragua sometieron a la C.I.J. en 1958 el Asunto de la Sentencia Arbitral del Rey de España de 1906, respecto de la cual Nicaragua alegaba la nulidad. La C.I.J. rechazó los fundamentos invocados por ese país y destacó que, en su opinión, "Nicaragua, por sus declaraciones expresas y por su comportamiento, reconoció la validez de la sentencia y carece del derecho de renegar de este reconocimiento para impugnar la validez de la sentencia". (I.C.J. Reports 1960, p. 213). También rechazó los fundamentos del exceso de poder en que habría incurrido el árbitro. Otro caso derivó del Acuerdo de París celebrado en 1930, entre Hungr ía con Checoslovaquia, Rumania y Yugoeslavia para someter a la C.P.J.I. $\sin$ compromiso especial, las impugnaciones relativas a la validez de las sentencias pronunciadas por los Tribunales Arbitrales Mixtos que habían funcionado entre esos Estados.

Las Reglas Modelo de la C.D.I., 1958 precisan que la demanda de nulidad suspenderá la ejecución de la sentencia, a menos que el tribunal que conozca de ella decida otra cosa. 
El arbitraje, facultativo $u$ obligatorio, no ha sido desplazado de la práctica internacional por la existencia de la Corte Internacional de Justicia. A pesar de críticas que se manifiestan a su operatividad actual, asuntos recientes aparecen resueltos o sometidos a este procedimiento, incluso por Estados en desarrollo (Asunto de Delimitación de la Plataforma Continental entre Guinea y Guinea Bissau, 1985, R.G.D.I.P., 84, 1985, pp. $481-537$ y Asunto del Territorio de Taba, entre Egipto e Israel, 1986, pendiente de solución). De acuerdo con Caflisch (L'Avenir de l'Arbitraje Interetatique". Loc. cit., pp. 42-43), los países del Tercer Mundo y socialistas podrían ver disminuidos sus temores frente a la solución judicial mediante la utilización del arbitraje facultativo, por la flexibilidad inherente que les permite mantener un amplio control en la composición del tribunal, el desarrollo del proceso, su publicidad y en cuanto al derecho aplicable.

\section{PARTL: III}

\section{La solución jurisdiccional: Tribunales permanentes}

\section{Antecedentes generales}

La creación de tribunales o cortes permanentes está vinculada a las organizaciones internacionalls, bajo cuya protección se ha garantizado su funcionamiento. La Conferencia de La Haya de 1907 intentó establecer dos jurisdicciones permanentes: un proyecto de Corte de justicia arbitral, fracasado y una Corte Internacional de Presas que no funcionó jamás (Conven ción XII).

Un esfuerzo notable constituyó la Corte de Justicia Centroamericana, creada en 1907, por Costa Rica, Guatemala, Honduras, Nicaragua y El Salvador (American Journal of International Law. Suppl, 1908, Vol. 2. pp. 231-243). Sus competencias se extendian a "todas las controversias o cuestiones que entre ellas puedan sobrevenir, de cualquier naturaleza que sean y cualquiera que sea su origen" (Art. I) así como "las cuestiones que inicien los particulares de un país centroamericano contra alguno de los gobiernos contratantes, por violación de tratados o con convenciones y en los demás casos de carácter internacional, sea que su propio gobierno apoye o no dicha reclamación; y con tal que se hubieren agotados los recursos que las leyes del respectivo pais concedieren con- 
tra tal violación, o se demostrare denegación de justicia" (Art. II). Tuvo 10 años de existencia, hasta el 12 de marzo de 1918. Conoció de 10 casos.

En virtud del Art. 14 del Pacto de la Sociedad de las Naciones, se crea en 1920 la Corte Permanente de Justicia Internacional. Al comenzar la Segunda Guerra Mundial, el estatuto de la C.P.J.I., aprobado por la asamblea, hab ía sido ratificado por 50 Estados, con excepción de EE.UU. y la URSS. La C.P.J.I. pose ía jurisdicción respecto de cualquier controversia de orden jurídico que le sometieren los Estados asi como, para emitir dictámenes u opiniones consultivas sobre cualquier controversia o asunto que le confiare el Consejo o la Asamblea. Su última sesión tuvo lugar en octubre de 1945 y por una resolución de la asamblea de la S. de N. (18IV-1946) enunció su disolución a partir del día siguiente de esá fecha (Dictionnaire. Loc. cit., p. 178).

\section{La Corte Internacional de Justicia}

(La Charte des Nations Unies, ed. por Jean-Pierre Cot et Allain Pellet. Par ís, Economica, 1985, pp. 1241-1296). Su creación fue prevista en la Conferencia de Dumbarton Oaks (1944), de la cual surge la proposición de que la futura organización de Naciones Unidas posea un tribunal permanente, así como que los Estados Miembros fueran ipso facto partes en el Estatuto. El Art. 92 de la carta de la ONU define la C.I.J. como "el órgano judicial principal de las Naciones Unidas" y señala que se rige por su Estatuto anexo, basado en el de la C.P.J.I. y que forma parte integrante de la Cartil.

De acuerdo con las caracter isticas de la organización int ernacional en la que se inserta, la C.I.J. posee una competencia general, a diferencia de otras jurisdicciones internacionales de competencia restringida (Infra, IV Parte), que se crean en una organización o sistema con fines limitados o específicos.

La creación de la C.I.J. como entidad diferente de la C.P.J.I.. fue propuesta por el comité de juristas encareada de examinar este tema, presidido por el jurista francés J. Basdevant, antes de la Conferencia de San Francisco. Razones políticas. como la exclusión de los Estados ex-cnemigos que eran partes del fistatuto de lit 
C.P.J.l., de toda cooperación internacional y razones técnicas, como la disolución de la $\mathrm{S}$. de $\mathrm{N}$., favorecieron la creación de un nuevo tribunal. No obstante que no se trata del mismo tribunal, el Estatuto de la C.I.J. es casi idéntico al de la C.P.J.I.; el reglamento de ésta sirvió de base al de la C.I.J. y lo que es más interesante, la C.I.J. ha recogido la jurisprudencia de su antecesora como parte de la jurisprudencia de la propia Corte.

La sucesión entre ambos tribunales se refleja en el Art. 36. párr. 5 del Estatuto que señala que "Las declaraciones hechas de acuerdo con el Artículo 36 del Estatuto de la Corte Permanente de Justicia Internacional que estén aún vigentes, serán consideradas, respecto de las partes en el presente Estatuto, como aceptación de la jurisdicción obligatoria de la Corte Internacional de Justicia por el periodo que aún les queda en vigencia y conforme a los términos de dichas declaraciones".

En la práctica la C.I.J. ha tenido menos actividad que la C.P.J.I., siendo notable la reticencia de muchos Estados, a aceptar su jurisdicción obligatoria.

La C.I.J. se reunió por primera vez en 1946; en aplicación de su Estatuto elaboró su Reglamento, aprobado el 6 de mayo de 1946 y enmendado en 1972 y 1978 . El primer asunto contencioso que conoció la C.I.J. fue el del Estrecho de Corfú. iniciado en 1947; por la vía consultiva, el primer asunto que se le confió fue el de las Condiciones de Admisión como miembro de las Naciones Unidas: Art. $4^{\circ}$ de la Carta de la ONU, en 1948.

Su sede se encuentra en La Haya, tal como la C.P.J.I.

a) Composición de la C.I.J.

De acuerdo con el Art. 2 del Estatuto, la corte es un cuerpo de magistrados independientes elegidos, sin tener en cuenta su nacionalidad, de entre personas que gocen de alta consideración moral, que reúnan las condiciones requeridas para el ejercicio de las más altas funciones judiciales en sus respectivos pa íses, o que sean jurisconsultos de reconocida competencia en materia de derecho internacional". 
Quince miembros componen la C.I.J., ninguno de los cuales puede tener la misma nacionalidad. Gozan de total independencia de los gobiernos y están protegidos por privilegios e inmunidades semejantes a las que el Derecho Internacional confiere a los agentes diplomáticos (Art. 19. Estatuto). Los jueces gozan de inamovilidad y tienen como contrapartida la obligación de no cjercer función práctica o administrativa alguna, ni dedicarse a ninguna otra ocupación de carácter profesional (Art. 16. Estatuto). No pueden ejercer funciones de agente. consejero o abogado en ningún asunto (Art. 17. Estatuto).

Los jueces se renuevan por tercios, correspondiendo a cada uno de ellos un periodo de 9 años; son reclegibles. Al asumir su función, cada juez declara solemnemente. en sesión pública, que cjercerá sus atribuciones con toda imparcialidad y consciencia.

La eleción de los jueces.-. Se realiza separada y paralelamente por la Asamblea General y el Consejo de Seguridad, órganos de la ONU que tienen un poder de codecisión para estos efectos. En el Consejo de Seguridad no se aplica el veto de los miembros permanentes. Cada órgano elige los candidatos por mayoría absoluta (Art. 10, Estatuto), lo cual asigna un equilibrio politico de intereses y representaciones.

Pueden realizarse hasta tres sesiones para las elecciones. Si después de una tercera sesión aún quedan vacantes, puede constituirse una comisión conjunta compuesta de seis miembros (tres por cada órgano), a petición de la Asamblea General o del Consejo de Seguridad, con el objeto de escoger, por mayoría absoluta de votos, un nombre para cada plaza aún vacante. Este nombre se someterá a la aprobación respectiva de los órganos indicados. Esta comisión conjunta puede acordar unánimemente el nombre de una persona que satisfaga las condiciones requeridas para ser juez, aunque no figure en la lista de candidatos designados por los "grupos nacionales" a que se refiere el Art. 4 del Estatuto y confeccionada por el secretario general. Finalmente, si la comisión conjunta concluye que no logrará asegurar la elección, los miembros de la C.I.J. ya electos lenarán las plazas vacantes, escogiendo a candidatos que hayan recibido votos en la Asamblea General o en el Consejo de Seguridad (Art. 12, Estatuto). No se ha utilizado este procedimiento. 
Como una forma de garantizar la independencia de los jueces, en el proceso de postulación de candidaturas, no intervienen directamente los gobiernos, sino los "grupos nacionales" de la Corte Permanente de Arbitraje (lista de miembros que se ofrecen como posibles árbitros) quienes deben indagar que se trate de personas que gocen de alta consideración moral y que reúnan los requisitos para el ejercicio de las más altas funciones judiciales en sus respectivos países, o que sean jurisconsultos de reconocida competencia en materia de Derecho Internacional (Art. 2, Estatuto). A fin de permitir la participación en este proceso de Estados que no son miembros de la C.P.A., el Estatuto prevé la formación de "grupos nacionales" designados por los gobicrnos de Estados partes en el Estatuto, para el sólo efecto de proponer candidatos.

A fin de hacer efectiva la universalidad en la composición de la corte, debe considerarse en la elección de los jueces que estén representadas las grandes civilizaciones y los principales sistemas juridicos del mundo (Art. 9, Estatuto). En la práctica, ha habido siempre un juez de la nacionalidad de cada miembro permanente (salvo el caso de China de ciertos momentos), así como se ha aplicado el principio del "reparto geográfico equitativo" para su designación, propio de las técnicas que rigen los órganos el sistema de la ONU.

Jueces ad hoc. Se trata de jueces ocasionales, designados especialmente para un determinado litigio.

Su función cesa junto al término del proceso para el cual fue designado. La institución del juez ad hoc en asuntos controvertidos (Art. 31, Estatuto) y en procedimientos consultivos (Art. 68 del Estatuto y 89 del Reglamento revisado) ha sido un tema controvertido para quienes desean suprimirla para acrecentar la imparcialidad de la corte y quienes, desean mantenerla. Una posición intermedia ha sido sugerida con el fin de suprimir el juez ad hoc al mismo tiempo que se excluirían los jueces "nacionales" de las partes. En cualquiera de estos casos, el objetivo que se busca es la igualdad de las partes (Cross, L. "The International Court of Justice: Consideration of Requirements for Enhancing its Role in the International Legal Order". The Future of the International Court (1) Justice, ed. By Gros, L. Vol. 1. 1976. pp. 61-64). 
La opinión que prevalece es la de que el juez ad hoc garantiza una buena administración de justicia, sobre todo teniendo en cuenta que no se concibe una recursación del juez "nacional" de la otra parte por el mero hecho de que exista coincidencia de nacionalidad. Gros (IBID) expone opiniones constructivas acerca de la función de estos jueces; por una parte, ellos cumplen una función útil al proporcionar un conocimiento local y un punto de vista nacional. Otra perspectiva aprecia en ellos su participación en la formulación del fallo, representando los intereses de los países que los han designado. Sin duda la mantención de esta institución es un homenaje a la soberanía del Estado.

La designación del juez ad hoc puede recaer en una persona que no posea la nacionalidad del Estado litigante. Esto ha ocurrido en varios asuntos, entre ellos España y Bélgica lo hicieron en el Asunto de la Barcelona Traction; Nicaragua en el de las Actividades Militares y Paramilitares en Nicaragua y Túnez, en el Asunto de Revisión e Interpretación de la Sentencia del 24 de febrero de 1982 (sobre la Plataforma Continental con Libia). Siendo un juez dotado de las mismas prerrogativas que los demás miembros de la corte, el juez ad hoc puede sostener una posición que no coincida plenamente con la del Estado que lo designó. Fue el caso del jues. ad hoc designado por Túnez en el Asunto de la Revisión e Interpretación de la sentencia del 24 de febrero de 1982, antes citado (1.C.J. Reports 1985, p. 247).

La designación del juez ad hoc es una facultad a la cual pucden renunciar las partes. Si los Estados hacen causa común, sólo pueden designar un juez ad hoc. La corte decide si procede nominar a más de un juez en este caso. Por ej. en los "Asuntos de la Competencia en Materia de Pesquerías" (Reino Unido y Rep. Federal de Alemania contra Islandia) la C.I.J. rechazó la solicitud alemana de designar un juez ad hoc porque su causa cra idéntica a la británica (Reports 1973, p. 51,7).

Tratándose de asuntos consultivos, tanto la C.P.J.I. como la C.I.J. han admitido jueces ad hoc, pero con reticencia. Fue un tema muy controvertido en el Asunto del Sahara Occidental, la C.I.J. aceptó la designación de un juez ad hoc de parte de Marruccos fundándose en que "una cuestión jurídica estaba pendiente". de acuerdo con el tenor del Art. 89 del Reglamento de 1972 (hoy 
Art. 102, $\mathrm{N}^{\circ}$ 3). Rehusó aceptar una nominación semejante de parte de Mauritania (Reports 1975, p. 8). España tenia un juez "nacional". En la Opinión Consultiva de Namibia, la C.I.J. rechazó la petición de Sudáfrica para esta designación (Reports 1971, p. $13)$.

b) Competencias

Competencia Contenciosa (Rosenne, Sh. The Law and Practice of the International Court. Vol. 1965, pp. 332-359)

RATIONE PLRSOVAE.- La pregunta de quién puede actuar ante la C.I.J. es respondida en el Capítulo II del Estatuto.

$\left.1^{\circ}\right)$ Sólo los Estados pueden ser partes en casos ante la corte (Art. 34, 1), $2^{\circ}$ ) En principio, la C.I.J. sólo está abierta a los Estados que son partes en el estatuto, todos los miembros de la ONU, de cuya carta el estatuto es un anexo. $3^{\circ}$ ) Pueden ser partes en el estatuto, de acuerdo con el Art. 92, 2 de la carta de la ONU, los Estados que no siendo miembros de la ONU cumplan con los requisitos que establezca en cada caso la Asamblea General, a recomendación del Consejo de Seguridad. De acuerdo con esta facultad, Suiza, San Marino, Liechtenstein son partes en el estatuto. Japón y la R.F.A. también lo fucron, antes de llegar a ser niembros de la ONU. $4^{\circ}$ ) Los Estados que, sin ser partes en el estatuto, de acuerdo con el Art. 35, 2 del estatuto, acepten las condiciones que establece el Consejo de Seguridad. Este las fijó por resolución de 15 de octubre de 1946 y faculta a Estados no-miembros a hacer declaraciones generales o particulares de compromiso en el cumplimiento de buena fe de las sentencias de la Corte así como, de acatamiento de todas las obligaciones que el Art. 94 de la carta impone a los Estados miembros. Albania. Italia, Cambodia, Ceylán. (Sri-Lanka), Finlandia, Italia, Japón, Laos, R.F.A. y Vietnam se han vinculado por este procedimiento.

Los particulares, personas naturales o jurídicas, no pueden ser partes ante la C.I.J.; sin embargo, numerosos calsos de protección diplomática han implicado abordar el tema de sus intereses y derechos.

Las organizaciones internacionales no pueden demandar. ni 98 
ser demandadas ante la C.I J .; pero la corte puede solicitarles colaboración para que le presten pública información relativa a casos que se litiguen ante la corte, y recibir la información que las organizaciones envien a iniciativa propia (Art. 35, 2 Estatuto). Otra vinculación puede derivarse del hecho de que ante la corte se discuta la interpretación del instrumento constitutivo de una organización internacional pública, o de una convención internacional concertada en virtud del mismo. El secretario de la C.I.J. comunica este hecho a la organización respectiva y le envia copia de todo el expedicnte (Art. 35, 3 ).

Competencia Facultativa: la regla general. Los Estados no están obligados a someterse a la jurisdieción de la C.I.J. sin su consentimiento. La C.I.J. no hace excepción a las reglas generales en la materia, situación que los Estados no han alterado desde 1920. L1 Art. 36, I aclara este principio "La competencia de la corte se extiende a todos los litigios que las partes se sometan y a todos los asuntos especialmente previstos en la Carta de las Naciones Unidas o en los tratados y convenciones vigentes".

En el asunto de la Plataforma Continental del Mar Egeo, Grecia c. Turquía, la C.I.J. reiteró la jurisprudencia de las cortes en el sentido de que el tribunal debe cerciorarse de la existencia del consentimiento, incluso mediante un examen de oficio, sobre todo cuando una de las partes se abstiene de comparecer (Turquía) (Reports 1978, Jurisdiction, p. 9). Fste asunto cra complejo por cuanto cl eventual consentimiento se habría manifestado en una serie de actos y comportamientos.

c) El consentimiento puede expresarse mediante:

Un compromiso o acuerdo especial para someter un asunto ya nacido. Por ej. el Asunto del Asilo, Colombia-Perú, por acuerdo de 1949. A diferencia del compromiso arbitral, éste no determina el procedimiento, ni la integración del tribunal. Sin embargo, en virtud de los Arts. 26 y 31 del estatuto, que permite la constitución de Salas compuestas de 3 o más magistrados para conocer de determinados asuntos. Las partes pueden solicitar que se constituyan estas salas. Por ej. Compromiso entre EE.UU. y Canadá en el Asunto de Delimitación de la Frontera Marítima en la Región del Golfo de Maine (I.C.J. Reports 1984, pp. 252 et ss.). Un 
Asunto Ironterizo entre Mali y Burkina Fasso, también fue sometido a una sala, en virtud de un compromiso 1983 (I.L.M. XXII, 1983. pp. 1252 y ss. El asunto fue decidido en 1986).

E1 compromiso debe precisar el objeto del litigio y las preguntas que se le formulan al tribunal. Pueden indicarse principios juridicos especiales que la corte tendrá o podrá considerar. La corte puede, no obstante, examinar que este punto no contradiga al Art. 38 de su estatuto.

Forum Promogatum. La jurisprudencia de la corte ha admitido que el consentimiento de un Estado para someter una controversia a su conocimiento puede derivar de cualquier "acto concluyente" del demandado, en especial, ocurrido después de haberse presentado la demanda ante el tribunal. En el Asunto del Canal de Corfú, Reino Unido v. Albania (Preliminary Objetions) (I.C.J. Reports 1947-1948, pp. 25-29). la C.I.J. sostuvo que la carta enviada a la corte por Albània el 2 de julio de 1947, constituía una aceptación voluntaria de su competencia. Mediante esa carta, Albania senalaba que "is prepared, not withstanding the irregularity in the action taken by the Government of the United Kingdom, to appear before the "Count". Esta decisión sigue la tesis sostenida por la C.P.J.I. en favor de la aceptación de cualquier forma de expresión del consentimiento.

La corte, al aceptar esta forma de otorgar competencia, se funda en el principio de la buena fe o del estoppel.

Debe distinguirse esta hipótesis de la que implica otorgamiento de competencia a la C.I.J. mediante acuerdos relativamente informales (Asunto de la Competencia en materia de Pesquerías. I.C.J. Reports 1973, p. 49). La C.I.J. no aceptó reconocer valor de acuerdo a un comunicado de prensa, sin firma, en el Asunto de la Plataforma Continental del Mar Egeo (I.C.J., Reports 1978, p. 3). Varias solicitudes han sido presentadas ante la C.I.J. con la esperanza de que se produzca un Forum Prorrogatum; Los 3 Asuntos de Incidentes aéreos planteados por EE.UU. (I.C.J. Reports 1956. pp, 6 y 9:1959, p. 276): los Asuntos sobre Antártica, planteadas por el Reino Unido contra Argentina y Chile (I.C.J. Reports, 1956. PP. 12 y 15). La Corte debió eliminar estos Asuntos de su rol por carcer de competencia. 
Competencia obligatoria: una excepción. La competencia de la C.I.J. puede ser obligatoria cuando dos o más Estados celebren un tratado que así lo establezca, para controversias actuales o futuras que se definen o determinan en términos generales (Art. 36, 1 del Estatuto). Este consentimiento expreso puede derivar de:

Una cláusula compromisoria contenida en un tratado cuyo objeto principal no es la solución de las controversias, con el fin de someter a la Corte toda controversia relativa a la interpretación y aplicación del tratado. En este caso, no se requiere de la conclusión de un compromiso especial, incluso, el hecho de que uno de los Estados parte que es demandado no comparezca en el juicio no priva al tribunal de competencia. Por ej. en el Asunto del Per sonal Diplomático de EE.UU. en Teherán, EE.UU. invocó una cláusula, similar entre otros fundamentos, contenida en un Tratado de Amistad, Comercio y Navegación con Irán, para afirmar la competencia de la Corte (I.C.J. Reports 1980).

En 1985, cerca de 250 Tratados conferían competencia a la C.I.J. (Anuario de la C.I.J. 1985);

Diversas convenciones multilaterales van acompañadas de "protocolos opcionales" por medio de las cuales, se acepta la competencia obligatoria de la C.I.J., en controversias entre las partes que versan sobre la materia regulada en la convención. Es el caso de las Convenciones de Viena sobre Relaciones Diplomáticas y Consulares.

Tratados Bilaterales o Multilaterales que versan exclusiva o principalmente con la solución de controversias, pueden reconocer competencia general o especial a la C.I.J. Por ejemplo, el Pacto de Bogotá, de 1948, que vincula a 13 Estados americanos y la Convención Europea, de 1957 para la solución pacífica de controversias.

La "cláusula facultativa de jurisdicción obligatoria" o "cláusula opcional" prevista en el Art. 36, 2 del Estatuto es la vía para que cualquicr Estado parte en el Estatuto, o autorizado por el procedimiento del Art. 36, del Estatuto, acepta unilateralmente la competencia de la C.I.J.: 
“2. Los Estados partes en el presente Estatuto podrán declarar en cualquier momento que reconocen como obligatoria ipso facto y sin convenio especial, respecto a cualquier otro Estado que acepte la misma obligación la jurisdicción de la Corte en todas las controversias de orden jurídico".

El mismo Art. 36 precisa que esta declaración puede hacerse incondicionalmente o bajo condición de reciprocidad por parte de varios o determinados Estados, o por determinado tiempo.

En el Asunto de las Actividades Militares y Paramilitares contra Nicaragua, la C.I.J. por 11 votos contra 5, señaló que no convenía exigir un formulismo excesivo respecto de la expresión del consentimiento (I.C.J. Reports 1984, Competencia, par. 113). Nicaragua en este Asunto se fundó en el Art. 36, 5 del Estatuto que expresa que las declaraciones hechas de acuerdo con el Art. 36 del Estatuto de la C.P.J.I. "que estén aún vigentes", serán consideradas, respecto de las partes en el presente Estatuto, como aceptación de la jurisdicción obligatoria de la C.I.J. por el periodo que aún les quede de vigencia y conforme a los términos de dichas declaraciones. A pesar de que el instrumento de ratificación de Nicaragua del Estatuto de la C.P.J.I., condición necesaria para que su declaración de aceptación de la jurisdicción de la C.P.J.I. tuviere valor juridico, no fue recibido por el tribunal, la C.I.J. consideró que ese país había prestado su consentimiento a dicha jurisdicción. La Corte examinó y otorgó valor probatorio a diversos indicadores que demostrarían la validez de esa declaración imperfecta.

Al 2 de encro de 1986, 56 Estados han hecho declaraciones de acuerdo con el Art. 36, 2 del Estatuto. De éstas, 11 han caducado o cesado de estar vigentes; entre éstas las de Francia (1974) y EE.UU. (1985).

La cláusula funciona sobre la base de la reciprocidad, lo que implica que, en caso de demanda unilateral, la C.I.J. no se declara competente hasta tanto no haya verificado que ambos Estados están ligados por una declaración de aceptación, de igual extensión y alcance.

La cuestión de las reservas a la declaración. Las reservas que acompañan la cláusula opcional son frecuentes. Su alcance se refie102 
re a limitaciones o condiciones a la aplicación de la cláusula en cuanto al tiempo (controversias futuras, por ej.), materia (excluyendo determinadas materias, asuntos domésticos, por ej.) o indicando los Estados respecto de los cuales se aplicará o no se aplicará la declaración. En la práctica, los Estados seleccionan por esta vía, las controversias respecto de las cuales están dispuestos a ser demandados ante la C.I.J. En virtud de la reciprocidad, las reservas formuladas por un Estado, aprovechan o benefician a la otra parte.

Las reservas formuladas por EE.UU. junto a su declaración de 1946, no-vigente, constituyen un caso típico de salvaguardias a la soberanía: ". . this declaration shall not apply to.

a) disputes the solution of which the parties shall entrust to other tribunals by virtue of agreements already in existence or which may be concluded in the future; or

b) disputes with regard to matters which are essentially within the domestic jurisdiction of the United States of America as determined by the United States of Amorica; or

c) disputes arising under a multilateral treaty, unless

d) all parties to the treaty by the decision are also parties to the case before the court, or (2) the United States of America specially agrees to jurisdiction;"

La reserva (b), denominada "automática" ha sido muy criticada por su virtual efecto de invalidar toda la declaración en caso de que se invocase. En el Asunto de los Préstamos Noruegos, Francia v. Noruega (I.C.J. Reports 1957, p. 23), la Corte acogió la excepción noruega que hizo suya la reserva de Francia del mismo tenor de la "reserva automática" de EE.UU. y se declaró incompctente, aunque no se pronunció sobre la validez de la declaración de aceptación de la competencia. El juez Lanterpacht en cambio, en una Opinión individual, sostuvo la invalidez no solo de la reserva, sino que de la declaración en su conjunto (IBID, p. 34).

En virtud de la reciprocidad, EE.UU. no pudo demandar exitosamente a Bulgaria en un Asunto del incidente aéreo en territo- 
rio búlgaro, que causó muertes de nacionales de EE.UU (Gross, L. "Bulgaria invokes the Connally Amendment, A.J.I.L., 56, 1962, p. 357). Después que la Corte se declaró competente en el Asunto de las actividades militares y paramilitares en Nicaragua, 1984, el asesor jurídico del Departamento de Estado invocó estos antecedentes, entre otros, para demostrar que EE.UU. no habia tenido éxito jamás en sus intentos de demandar a otro Estado invocando la "cláusula opcional" y que no era conveniente para los intereses de ese pais mantenerla vigente ("Statement of Legal Adviser of State Department" Abraham D. Sofaer to Senate Foreign Relations Committe. Dec. 4, 1985, en Internacional Law Cases and Materials. Henkin, L. et al 2nd ed., pp. 46-48).

Finalmente, siendo la declaración hecha de conformidad con esta "cláusula" un acto jurídico vinculante, su modificación, revisión y caducidad se rigen por los principios del Derecho Internacional y por las propias disposiciones que contengan. Es así como, si al efectuar una declaración, el Estado señala que ésta no podrá ser modificada o denunciada sino de acuerdo con ciertas modalidades, plazos, etc. no pueden modificarse ulteriormente las disposiciones de la declaración sin que al mismo tiempo se respeten las modalidades y plazos establecidos previamente. La C.I.J. rechazó el efecto inmediato de la enmienda a su declaración de 1946, comunicada a la Corte el 6 de abril de 1984 por EE.UU., ya que aquella señalaba que permanecería vigente hasta seis meses después que se notificara su revocación (Asunto de las Actividades Militares y Paramilitares en Nicaragua. I.C.J. Reports 1984, competencia, par. 52-66).

Un tratado puede conferir a la Corte la competencia de un Tribunal de apelacion. Es el caso de la Convención sobre la Aviación Civil Internacional, 1944, que reconoce a la Corte la competencia para conocer apelaciones contra las decisiones del Consejo de la OACI (Asunto de la Competencia del Consejo de OACI, India/Paquistán. I.C.J. Reports 1972, p. 47).

La Corte puede también revisar fallos emitidos por tribunales administrativos internacionales, por la vía consultiva. No es propiamente el ejercicio de una función contenciosa.

Por otra parte, aunque se ha debatido el alcance del Art. 
36, 1 en lo que define como "asuntos especialmente previstos en la Carta de las Naciones Unidas" y su eventual vinculación con el Art. 36, 3 de la Carta que faculta al Consejo de Seguridad para hacer recomendaciones en favor del sometimiento a la C.I.J. de controversias de orden jurídica, no existe otra fuente de jurisdicción obligatoria ni en la Carta, ni el Estatuto que no sean las anteriormente expuestas.

d) PROCEDIMIENTO. La fuente de las reglas procesales, a diferencia del arbitraje, es el Capitulo III del Estatuto, complementado por el Reglamento que la propia Corte adoptó (1946) y puede enmendar (1972 y 1978).

Particularidades: $1^{\circ}$ ) El Procedimiento en rebeldia tiene lugar cuando una de las partes no comparece o se abstiene de defender su caso, situación en la cual la otra parte puede pedir a la Corte que decida en su favor (Art. 53,1). Antes de dictar su sentencia, la Corte debe asegurarse no sólo de que tiene competencia conforme a las disposiciones de los Arts. 36 y 37, sino también de que la demanda está bien fundada en cuanto a los hechos y al derecho (Art. $53,2)$; se ha constituido en práctica habitual la no comparecencia ante la C.I.J. frente a recursos unilaterales; por ej. Turquía, en el Asunto de la Plataforma Continental del Mar Egeo, Irán en el Asunto del Personal Diplomático y Consular de EE.UU. en Teherán, 1980; EE.UU. en el Asunto de las Actividades Militares y Paramilitares en Nicaragua, 1986, después que la C.I.J. se declaró competente.

$2^{\circ}$ ) Se admite en el procedimiento la intervención de un tercero "si un Estado considerase que tiene un interés de orden juridico que puede ser afectado por la decisión del litigio" (Art. $62 \mathrm{del}$ Estatuto y Art. 81 del Reglamento, que precisa el alcance del concepto de interés de orden jurídico). La Corte decide respecto de la petición de intervención. La intervención es de derecho si se trata de la interpretación de una convención en la cual son partes otros Estados además de las partes en litigio, los cuales son notificados por el Secretario del tribunal (Art. 63 del Estatuto). Si un tercero ejerce este derecho, la interpretación de la convención contenida en el fallo le es obligatoria.

La Corte, inspirada en un deseo de no extender indirectamen- 
te su competencia sin que se respete el principio del consentimiento de los Estados para el ejercicio de aquélla, ha rechazado varias solicitudes de intervención en asuntos recientes: de Malta, en el Asunto de la Plataforma Continental entre Libia y Túnez (Reports 1981, p. 19); de Italia, en el Asunto de la Plataforma Continental entre Malta y Libia (Reports 1984, pp. 1-28); de El Salvador, en el Asunto de las Actividades Militares y Paramilitares en Nicaragua (Reports 1984, Order, pp. 215-217).

$3^{\circ}$ ) La instancia ante la Corte tiene dos fases: una escrita y otra oral. El procedimiento escrito comprenderá la comunicación, a la Corte y a las partes, de memorias, contramemorias y, si fuese necesario, de réplicas, así como de toda pieza o documento en apoyo de las mismas. El procedimiento oral consiste en la audiencia que la Corte otorgue, a testigos, peritos, agentes, consejeros y abogados (Art. 43 del Estatuto). Los principios desarrollados en detalle en el Estatuto y su Reglamento, buscan garantizar la igualdad de las partes y la libre discusión de sus argumentaciones.

$4^{\circ}$ ) La Corte puede, en cualquier momento, comisionar a cualquier individuo, entidad, negociado, comisión $u$ otro organismo que ella escoja, para que haga una investigacion o emita un dictamen pericial (Art. 50 del Estatuto). Esto puede implicar incluso una visita al área litigiosa o lugar donde ocurrieron los hechos controvertidos.

$5^{\circ}$ ) La Corte puede borrar un asunto de su rol si aquél ha sido objeto de una decisión definitiva o si la parte demandante se desiste sin encontrar objeciones de la parte demandada. Este asunto puede volver a reinscribirse si el desistimiento no equivale a una renuncia definitiva a la reclamación inicial. Esto ocurrió en el Asunto de la Barcelona Traction, entre Bélgica y España.

e) PODERES de la Corte: Las competencias implicitas de la C.I.J. fueron expuestas por ella en el Asunto de los Ensayos Nucleares, Australia y Nueva Zelandia v. Francia (Reports 1974, pp. 253 y 463 ), en cuyo caso señaló que poseía un poder inherente que la autorizaba a adoptar cualquiera medida para asegurar que, si su competencia en cuanto al fondo de la controversia fuere establecida, su ejercicio no fuera fano, así como para asegurar la solución regular de cualquier punto en litigio.

106 
La facultad de la C.I.J. de decidir sobre su propia competencia, está expresamente consagrada en el Art. 36, 6 del Estatuto. "En caso de disputa en cuanto a si la Corte tiene o no jurisdicción, la Corte decidirá".

El fundamento de este principio se encuentra en la calidad de órgano judicial, que posee la Corte, tal como se le atribuye a los tribunales arbitrales. Esta facultad fue enunciada en el Tratado Jay entre EE.UU y el Reino Unido de 1794 y fue expresamente incorporado en la Convención de La Haya de 1907 para el Arreglo Pacífico de los Conflictos Internacionales, cuyo Art. 73 señala: "El Tribunal estará autorizado para determinar su competencia interpretando el compromiso y las demás actas y documentos que puedan invocarse en la materia y aplicación de las reglas de derecho".

Las excepciones preliminares pueden ser planteadas por el Estado demandado a fin de impugnar la competencia de la Corte o la admisibilidad de la demanda, o presentar toda otra excepción respecto de la cual solicita una decisión antes de que prosiga el procedimiento sobre el fondo.

La Corte debe decidir acerca de estas excepciones in limine $1 i$ $t i s$, antes de pasar al examen del fondo del asunto, excepto cuando decide unir la excepción al fondo. En el Asunto de los Ensayos Nucleares Franceses, se produjo en debate acerca de si la existencia de normas consuetudinarias que prohibieran los ensayos era o no una cuestión preliminar (I.C.J. Reports 1973, p. 288 y p. 304, I.C.J. Reports 1974, pp. 304305).

Las excepciones relativas a la competencia pueden fundarse en la incompetencia ratione personae; ratione materiae (no existe una controversia jurídica); ratione temporis (por expiración del plazo de vigencia de un tratado o una declaración unilateral, los hechos invocados ocurrieron antes de la entrada en vigor del instrumento que confiere jurisdicción a la Corte y no los cubre) etc.

Por ej. el Asunto de las Actividades Militares y Paramilitares en y contra Nicaragua, EE.UU. invocó 5 causales de inadmisibilidad de la demanda nicaragüense, relativas principalmente a la naturaleza del conflicto, más apropiado para un examen del Consejo de Seguridad, y la existencia de mecanismos de solución de controver- 
sias de alcance regional que estaban operando. La Corte rechazó estos argumentos y dió curso a la demanda nicaragüense (Reports 1984, parr. 84-108).

Una de las causales de inadmisibilidad puede ser asimismo, la fal ta de interés en la acción. En un fallo controvertido, la Corte rehusó conocer del asunto relativo al Sudoeste africano, en 1962 , basándose en la carencia de un interés juridico directo de los demandantes (Reports 1962, p. 319).

El interés en la acción fue examinado ya en el primer fallo de la C.P.J.I. en el Asunto Wimbledon, recnociéndose a las Potencias demandantes "un interés evidente en la ejecución de las estipulaciones relativas al Canal de Kiel, ya que todas ellas tienen flotas y buques mercantes que enarbolan sus pabellón" (Serie A, $\mathrm{N}^{\mathbf{0}} 1$, p. 20). Por otra parte, en el Asunto relativo al Camerún Septrentrional, (Excepciones Preliminares, Fallo de 2 de diciembre de 1963), la C.I.J. rehusó admitir que el interés invocado por la parte demandante (Camerún) constituía un interés judicial, susceptible de ser objeto de una decisión jurisdiccional. Camerún buscaba obtener una satisfacción moral en la forma de un fallo declaratorio de la Corte, respecto de una convención que ya no estaba vigente (Reports 1963 , pp. 33-34) lo que a juicio del tribunal privaba a la controversia de su objeto.

Siguiendo a De Visscher (Aspects Récents du Droit Prodédurale de la Cour Internationale de Justice. París. Pedone, 1966, pp. 68-72), puede presentarse en el Derecho Internacional Contemporáneo solicitudes para que la Corte pronuncie un fallo declaratorio, cuyo carácter especifico es de definir generaliter, el alcance de una regla consuetudinaria o convencional, o sea, fuera de cualquier referencia a hechos o situaciones que pertenezcan al pasado. El interés que motiva un fallo declarativo busca el reconocimien to de una situación jurídica de una vez por todas y con efecto obligatorio para las partes. Por otra parte, esta noción de interés general, que no implica necesariamente reconocer un actio popularis, puede encontrarse garantizada en ciertas órdenes de interés claramente institucionalizados por efecto de convenciones colectivas, concluidas en el interés general de la humanidad y la civilización. De estas convenciones surgiria un interés funcional que abriría a los Estados miembros de una colectividad, la defensa mediante un 
control objetivo de los fines superiores de un orden jurídico en el cual participan.

Por otra parte, la facultad de ordenar Medidas Provisionales está indicada en el Art. 41 del Estatuto que prevé la facultad para indicar, si considera que las circunstancias así lo exigen, las medidas provisionales que deban tomarse para resguardar los derechos de cada una de las partes". La dictación de estas medidas es facultativa, si la C.I.J. estima que los derechos que son objeto de la demanda están amenazados de un perjuicio irreparable. Por ej. en el Asunto del Personal Diplomático y Consular de EE.UU. en Teherán, la Corte indicó diversas medidas provisionales por razones básicamente humanitarias fundadas en el derecho vigente, entre ellas, la liberación de los rehenes y el restablecimiento de las inmunidades, privilegios y protección al personal diplomático y consular (Reports 1979, párr. 47).

La jurisprudencia de la C.I.J. ha señalado que puede decretar estas medidas, aunque no se haya determinado definitivamente su competencia en cuanto al fondo, si los fundamentos de ésta invocados por el requirente parecen constituir prima jacie una base sobre la cual podria fundarse esta competencia. Las medidas adoptadas se notifican a las partes y al Consejo de Seguridad.

¿Están amparadas estas medidas por la autoridad de cosa juzgada? Puede sostenerse que su rechazo, sobre todo cuando están destinadas a detener un agravamiento de una situación conflictiva, puede a carrear la responsabilidad internacional.

Para la indicación de medidas provisionales, la Corte ha exigido que concurran dos elementos: la inminencia de un perjuicio irreparable y el riesgo de un agravamiento de la controversia. Por estas razones, no acogió la solicitud griega de decretarlas en el Asunto de la Plataforma Continental del Mar Egeo (Reports 1976 , párr. 41-42), precisando que ambos Estados estaban obligados a acatar una resolución (395) del Consejo de Seguridad, de carácter imperativo, que las exhortaba a respetar el principio de la solución pacífica de las controversias; además, señaló que no podía presumirse que los Estados involucrados no acatarán la resolución del órgano de la ONU responsable de la mantención de la paz y seguridad. 
f) El Derecho aplicable. De acuerdo con el Art. 38 del Estatuto, la función de la Corte "es decidir conforme al derecho internacional las controversias que le sean sometidas", aplicando las fuentes que enuncia el mismo Artículo. Puede ocurrir que en la petición del demandante o las partes de acuerdo, se busque un pronunciamiento de la Corte acerca de determinados principios, como ha ocurrido en asuntos en que se ha debatido el Derecho del Mar; incluso, pueden las partes ampliar el alcance del derecho internacional facultando a la Corte para tener en cuenta nuevas tendencias del orden jurídico internacional, como fue el caso del Asunto relativo a la Plataforma Continental entre Túnez y Libia (Reports 1982).

Las partes puden autorizar a la Corte a decidir ex aequo et bono, es decir, en equidad. Es interesante constatar que ta Corte ha rehusado la facultad de determinar un régimen de aplicación para el futuro entre las partes y que prevenga la reaparición de los factores de una controversia entre ellos. Por ej. en el Asunto entre Francia y Suiza sobre las Zonas Francas, la C.P.J.I. precisó que no le competía elaborar su régimen económico; éste, a su juicio, no era una cuestión de derecho sino un asunto que dependía del juez o de intereses económicos recíprocos respecto de los cuales ningún gobierno podría aceptar el control de un órgano externo (Ordenanza del 6 de diciembre de 1930).

La Corte puede ser requerida para dictar una sentencia puramente declarativa del derecho vigente, la cual deja a los Estados la aplicación práctica de los principios enunciados. Ha sido el caso de la sentencia en el Asunto de la Plataforma Continental del Mar del Norte (Reports 1969 1969, p. 53) y de la Plataforma Continental entre Túnez y Libia (Reports 1982, p. 92).

En un Asunto relativo al Camerún Septentrional, la C.I.J. rehusó ejercer la función judicial para pronunciarse acerca de una norma internacional hipotética; si en una sentencia, indicó la Corte, ella define una regla de derecho internacional consuetudinario o interpreta un tratado vigente, esa sentencia resulta aplicable en el futuro. Pero, en el Caso específico, existe una controversia relativa a la interpretación y aplicación de un tratado. . . que terminó y no está vigente. No cabe ninguna posibilidad de ese tratado sea objeto de un acto de interpretación o de aplicación conforme a una sentencia emitida por la Corte (Reports 1963, pp. 36-38). 
g) La Sentencia de la C.I.J. Todas las decisiones de la Corte se adoptan por mayoría de votos de los magistrados presentes. En caso de empate, decidirá el voto del Presidente o del magistrado de que lo reemplace (Art. 55, Estatuto). En dos oportunidades la Corte ha reunido a este mecanismo de decisión. En el Asunto del Lotus, en 1927 y en el Asunto del Sudoeste Africano, en 1966.

Forma de la sentencia: La sentencia debe ser razonada e indicar los nombres de los magistrados que hayan tomado parte en él (Art. 55, Estatuto). Se distinguen tres sanciones en un fallo de la C.I.J. La primera sostiene la individualización del asunto, indicación de las partes y sus representantes, exposición de los hechos, reproducción de las conclusiones y argumentos jurídicos de las partes. La segunda sección comprende una exposición de motivos ("el fallo será motivado"). La tercera sección contiene la parte dispositiva que es en definitiva la solución que impone la Corte para el asunto controvertido. Los magistrados pueden expresar sus opiniones disidentes o individuales, las cuales se adjuntan al fallo. La parte dispositiva debe indicar los nombres de los magistrados que concurren a la decisión.

Naturaleza y Alcance de la sentencia; el fallo es definitivo e inapelable (Art. 60, Estatuto), Produce autoridad de cosa juzgada, no es obligatoria sino para las partes en litigio y sólo para el caso que ha sido decidido.

La ejecución de la sentencia de la Corte. Como en el arbitraje, este es un tema que interesa a la jurisdicción permanente y a la organización internacional en la cual se inserta.

El Art. 13, 4 del Pacto de la Sociedad de las Naciones estableció que los miembros de la sociedad se comprometían a ejecutar de buena fe las sentencias y a no recurrir a la guerra contra otro miembro que la acatare. A falta de ejecución, el Consejo podrá proponer las medidas tendientes a asegurar ese cumplimiento. Además de limitar el recurso a la guerra durante un plazo determinado, el Pacto aceptaba un principio de ejẹcución forzosa de las sentencias internacionales. Durante la vigencia del Estatuto de la C.P.J.I. primó, en todo caso, una distinción entre el concepto de cosa juzgada y de fuerza ejecutoria de la sentencia. 
La Carta de la ONU avanza una solución a este respecto y en su art. 94 señala que " 2 . Si una de las partes en su litigio dejare de cumplir las obligaciones que le imponga un fallo de la Corte, la otra parte podrá recurrir al Consejo de Seguridad, el cual podrá, si lo cree necesario, hacer recomendaciones o dictar medidas con el objeto de que se lleve a efecto la ejecución del fallo". No se aplica a las sentencias interlocutorias, ni a las ordenanzas.

Fste Art. 94 sólo alude a los fallos de la C.I.J. y no de otros tribunales, a diferencia del Pacto de la S. de N. La funcionalidad de este sistema es más bien teórica; en la práctica, pocos fallos han obtenido un rechazo total de la parte perdedora. Por ej., cl fallo del Asunto del Estrecho de Corfú, que determinó el monto de las reparaciones debidas por Albania, caso del cual derivó el Asunto del Oro Monetario retenido en Roma en 1943. Tampoco fueron acatados los fallos en los Asuntos de Competencia en materia de Pesquerías y recientemente EE.UU. ha rechazado el fallo de la Corte en el Asunto de Fondo de las Actividades Militares y Paramilitares en Nicaragua, 1986.

En general, el Art. 94, 2 de la Carta ofrece cierta imprecisión en cuanto al tipo de recomendación o de medidas que el Consejo pudiere adoptar; no puede contravenirse en ningún caso el carácter definitivo y obligatorio del fallo.

Recursos. De acuerdo con el Estatuto de la Corte, cabe interponer el recurso de Interpretación a solicitud de cualquiera de las partes, en caso de desacuerdo sobre el sentido o el alcance del fallo. Este desacuerdo debe ser real y deriva de dificultades que se originen en la práctica, no puede tratarse de un simple desacuerdo con el fallo. Por ej. la Corte rechazó el recurso de interpretación presentado por Colombia al día siguiente de emitido el fallo en el Asunto del Derecho de Asilo (Reports 1950, pp. 401-403). Como consecuencia de estos fallos, una solicitud formulada por ambas partes, Colonibia y Perú. Augusto Haya de la Torre (Reports 1951, p. 83), condujo a la Corte a precisar que no podía dar consejos prácticos acerca de los diversos cursos que podrán seguirse para poner término al asilo, pero las Partes serían capaces de encontrar una solución satisfactoria y práctica a ese asunto inspirándose en principios de cortesía y buena vecindad. 
El Estatuto dispone asimismo que puede pedirse "la revisión de un fallo cuando la solicitud se funde en el descubrimiento de un hecho de tal naturaleza que pueda ser factor decisivo y que, al pronunciarse el fallo, fuera desconocido de la Corte y de la parte que pida la revisión, siempre que su descubrimiento no se deba a neglirencia". El recurso puede interponerse dentro del término de seis meses después de descubierto el hecho nuevo y sólo hasta 10 años desde la fecha del fallo (Art. 61, Estatuto).

2) La Función Consultiva. De acuerdo con el Art. 96 de la Carta de la ONU, la Asamblea general o el Consejo de Seguridad podrán solicitar de la Corte que emita una opinión consultiva sobre cualquier cuestión jurídica. También pueden solicitar opiniones consultivas sobre cuestiones jurídicas que surjan dentro de la esfera de sus actividades, "los otros órganos de las Naciones Unidas y los organismos especializados que en cualquier momento sean autorizados para ello por la Asamblea general". El Cap. IV del Estatuto desarrolla estos principios.

Solicitud ante la C.I.J. A diferencia de la función contenciosa, la consultiva no está abierta a los Estados, lo cual ha sido justificado como una forma de evitar que se solicita a la Corte una opinión jurídica que prejuzgue sobre un asunto pendiente con otro Estado, eludiendo el consentimiento de éste. Si la opinión fuese requerida por todas las partes interesadas en un asunto, se tratará en realidad del ejercicio de una función contenciosa.

La solicitud puede ser presentada por la Asamblea General, el Consejo de Seguridad, órganos de la ONU y organismos especializados autorizados por la Asamblea General. La C.I.J. ha señalado que el concepto "órganos de la ONU" debe entenderse como órganos principales y subsidiarios (Opinión de 12 de julio de 1973. Solicitud de Reforma de la Sentencia $N^{\circ} 158$ del T.A.N.U., (Asunto Fusla), Reports 1973, pp. 172-174). 4 órganos de la ONU y 15 organismos especializados UNESCO, OMI, OMS, entre otros, han sido autorizados a presentar solicitudes en este ámbito. El Comité de Naciones Unidas sobre solicitudes de Revisión de las sentencias del Tribunal Administrativo fue creado especialmente en $1955 \mathrm{con}$ el fin de solicitar opiniones consultivas para la revisión de las decisiones del Tribunal Administrativo de Naciones Unidas. Res. A.G. 957 (X), 1955. 
En cuanto al procedimiento de adopción de la resolución que somete una cuestión a la opinión consultiva de la C.I.J., la Asamblea General no la trata como una cuestión importante que requiere el voto de una mayoría de dos tercios de miembros presentes y votantes (Art. 18, Carta). El Consejo de Seguridad ha solicitado una opinión consultiva en 1970, sobre el Asunto de Namibia, en la cual no se especificó si se trata de una cuestión de fondo y por lo tanto susceptible de veto.

Competencia Consultiva Ratione Materiae: una solicitud de la Asamblea General o del Consejo de Seguridad puede referirse a "cualquier cuestión jurídica". En cambio las que formulen los otros órganos de la ONU y los organismos especializados, sólo pueden referirse a "cuestiones jurfdicas que surjan dentro de la esfera de sus actividades" (Art. 96).

La Corte examinará si la solicitud que se le formula se refiere a una cuestión jurídica pendiente entre dos o más Estados. Por ej. en el Asunto del Sahara Occidental, España planteó que la cuestión que se preguntaba a la C.I.J. se refería a una controversia entre Estados y que la Corte debia inhibirse de conocer del caso por carecer del consentimiento de las partes. La C.I.J. rechazó los argumentos españoles y emitió un dictamen (I.C.J. Reports 1975, par. 25-47).

Sobre la competencia consultiva la C.I.J. se pronunció en el Asunto de la Interpretación de los Tratados de Paz con Bulgaria, Hungría y Rumania (I.C.J. Reports 1950, p. 71) precisando que "El consentimiento de los Estados partes en una controversia es la base de la competencia de la Corte en asuntos contenciosos. Es diferente la situación respecto de los procedimientos consultivos aún cuando la solicitud de una Opinión se refiera a una cuestión legal pendiente entre los Estados. La respuesta de la Corte tiene sólo un carácter consultivo: como tal, no tiene fuerza obligatoria. Se desprende de esto que ningún Estado, sea miembro o no de ONU, puede prevenir la emisión de una Opinión Consultiva que la ONU considere deseable para determinar un curso de acción. La Opinión de la Corte no es dada para los Estados, sino para el órgano que está capacitado para requerirla; la respuesta de la Corte, "órgano de la ONU", representa su participación en las actividades de la organización, y en principio, no deber ́a ser rehusada". 
El caso lifder que ilustra acerca de la negativa de la Corte en emitir una Opinión, fundada en que la solicitud estaba vinculada a un litigio en el cual una de las partes era un Estado no-miembro de la Sociedad de las Naciones (URSS) es el Asunto de Carelia Oriental 1923, (P.C.I.J. Série B N 5).

Otras razones decisivas para que la Corte rehuse adoptar un dictamen consultivo pueden ser, que la cuestión no posea naturaleza jurídica, o que el asunto sea de aquellos que pertenecen esencialmente a la jurisdicción interna de la competencia de un Estado, o como se ha indicado precisamente, que por la vía consultiva se pretenda resolver el fondo de un litigio pendiente.

Naturaleza de la Opinión Consultiva. No posee el carácter de un acto jurisdiccional, y en consecuencia no es obligatoria como un fallo. Sin embargo, no adolece de valor jurídico y debe ser tenida en cuenta por el órgano que la requirió para enclarecer una cuestión y adoptar una decisión. La función de constatar el derecho otorga un gran valor jurídico a los dictámenes consultivos. No es una función de control judicial, ni de apelación de decisiones adoptadas por órganos de la ONU.

Puede ocurrir que una convención reconozca valor obligatorio a un dictamen consultivo. Por ej.: la Convención sobre Privilegios e Inmunidades de Naciones Unidas, 1946, en su sección 30, para el caso de controversias entre la ONU y un miembro de ésta. Una fórmula especial también contempla el Art. 37, 2 del Acta constitutiva de la OIT para controversias relativas a la interpretación de la Carta constitutiva o convenciones concluidas bajo el auspicio de la OIT. Otro caso específico es el de los Tribunales Administrativos de la OIT y de Naciones Unidas, cuyos fallos son apelables por la vía consultiva, teniendo el dictamen valor obligatorio.

\section{PARTE IV}

\section{Jurisdicciones Internacionales de Competencia Restringida}

De manera sumaria, se presentarán los casos más importantes de tribunales internacionales especializados, tanto por el número de Estados que pueden requerir su actuación como por las mate- 
rias que pueden conocer. Ciertas jurisdicciones son creadas en el marco de una organización internacional o en forma de una convención multilateral para conocer y fallar controversias planteadas exclusivamente dentro del ámbito de aplicación de sus disposiciones.

Algunas de estas jurisdicciones tienen como característica que no se limitan a resolver controversias entre Estados, sino que admiten el acceso a particularidades y de organizaciones internacionales. Existe asimismo una variedad de derecho aplicable por estas jurisdicciones, dependiendo de la conven ción que le sirva de marco y cuyas disposiciones debe interpretar y hacer ejecutar.

De acuerdo con una distinción doctrinal, entre jurisdicciones administrativas $y$ no-administrativas, según si estén destinadas a resolver o no cuestiones relativas a la función pública internacional sobre la base del derecho interno de una organización, pueden considerarse los siguientes ejemplos de jurisdicción institucionalizada restringida.

1. Jurisdicción Administrativa Internacional:

a) En el sistema de la ONU, el Tribunal Administrativo de la Organización Internacional del Trabajo, cuya competencia no se limita a las controversias entre la OIT y sus funcionarios, sino que además a las que se susciten en el seno de otros organismos (UNESCO, OMS, FAO, O.M.M., UIT, GATT, O.I.E.A. entre otros). Respecto del funcionario requirente, el fallo es definitivo y sin apelación. En cambio la organización internacional puede solicitar la reforma del fallo mediante un dictamen consultivo de la C.I.J. Este dictamen posee fuerza obligatoria.

b) El otro tribunal de esta naturaleza es el Tribunal Administrativo de la ONU (T.A.N.U.), establecido por una resolución de 24 de noviembre de 1949 de la Asamblea General, en virtud de los Arts. 101 y 22 de la Carta. La competencia del Tribunal se extiende a las solicitudes que le presenten los funcionarios y agentes de la ONU contra decisiones del Secretario General que les conciernen. También puede conocer de los recursos que presenten funcionarios de instituciones especiali- 
zadas, de acuerdo con condiciones fijadas en acuerdos entre estas instituciones y el Secretario General de la ONU.

Los fallos que emite el T.A.N.U. son decisiones judiciales obligatorias, incluso para la Asamblea General de la ONU, aunque se trate de un órgano subsidiario. En 1955 se creó un Comité para examinar las solicitudes de reforma de las sentencias del T.A.N.U. presentadas por el Secretario General o un Estado miembro, integrado por representantes de Estados; si estima que la petición es fundada, el Comité puede solicitar un dictamen consultivo sobre la validez del fallo impugnado. Si la solicitud emana de un funcionario, puede dirigir su opinión a la Corte por medio del Secretario General. El dictamen de la C.I.J. es obligatorio.

Otros tribunales administrativos han sido creados en el Banco Mundial y en organizaciones regionales (OEA) u otras, en las cuales se han constituido comisiones de recursos. Por ejemplo, OTAN, Consejo de Europa, O.C.D.E.; U.E.D.; Agencia Especial Europea, etc.

\section{Jurisdicciones Internacionales No-Administrativas.}

Es la categoría más importante en cuanto al desarrollo del Derecho Internacional que representan. Se han manifestado especialmente en el ámbito de la protección de los derechos humanos y en las organizaciones regionales de integración económica.

a) En materia de Derechos Humanos, deben mencionarse:

- La Corte Europea de Derechos Humanos, creada en 1950 por la Convención de Roma, vigente para todos los Estados miembros del Consejo de Europa. Forma parte de un sistema de protección constituido por la Comisión Europa de Derechos Humanos y el Consejo de Ministros del Consejo de Europa.

Competencias: las solicitudes son planteadas primero ante la Comisión y un asunto puede derivar ante la Corte si fracasa la Comisión en su intento de lograr un arreglo amigable. Pueden recurrir ante la Corte, la Comisión, el Estado que tuvo la iniciativa de plantear un asunto ante ella, el Estado acusado y el Estado de na- 
cionalidad de la víctima, siempre que los Estados interesados hayan aceptado la competencia obligatoria de la Corte mediante una declaración unilateral (Art. 46 de la Convención). Los particulares no son partes ante la Corte.

El derecho aplicable por la Corte es el establecido en la Convención de Roma y sus 8 protocolos adicionales. En 1978, la Corte emitió su primer fallo en un asunto planteado por demanda de un Estado (Asunto Irlanda v. Reino Unido por Trato Inhumano y Tortura. I.L.M. XVII, 1978, 3, pp. 680-713).

- La Corte Interamericana de Derechos Humanos (Vargas Carreño, E. "La Corte Interamericana de Derechos Humanos" Perspectivas del Derecho Internacional Contemporáneo, Vol. II, Ed. por F. Orrego y J. Irigoin. Santiago, Instituto de Estudios Internacionales. Universidad de Chile, 1981, pp. 130-155). Creada por la Convención de San José de Costa Rica, en 1969. El Sistema Interamericano de protección de derechos humanos comprende también una Comisión, creada en la Carta de la OEA y perfeccionada en la Convención de San José. Como órgano jurisdiccional presenta un nivel más avanzado de institucionalización que la europea, por cuanto está integrada por siete jueces y admite la designación de un juez ad-hoc.

Competencias. La Corte posee competencia contenciosa y consultiva. En el primer caso puede conocer de un asunto que le someta la Comisión Interamericana de Derechos Humanos o un Estado Parte en la Convención que declare que reconoce la competencia de la Corte sobre todos los casos relativos a la interpretación de o aplicación de la Convención (Art. 62).

En cuanto a su función consultiva, puede actuar a solicitud de cualquier Estado miembro de OEA (Art. 64) y pronunciarse acerca de la interpretación de esta Convención o de otros tratados concernientes a la protección de los derechos humanos en los Estados Americanos. Puede ser consultada asimismo, acerca de la compatibilidad entre cualquier ley de un Estado miembro y esos instrumentos internacionales. La Corte ha emitido 8 opiniones consultivas hasta la fecha. 
b) En materia de derecho de la integración o comunitario, dos casos merecen indicarse:

- La Corte de Justicia de las Comunidades Europeas, creada en virtud del Tratado de Roma de 1957 como Corte común a las entidades integrantes de las Comunidades (Comunidad Europea del Carbón y del Acero; Comunidad Económica Europea y Comunidad Europea de Energía Atónica).

Competencias. - El Art. 164 del Tratado de Roma establece que la Corte de Justicia asegura el respeto del derecho en la interpretación y aplicación de ese Tratado. Este principio ha sido interpretado de manera que comprende el derecho comunitario derivado. Puede otorgársele competencia además por convenciones particulares. La competencia de la Corte es obligatoria.

La Corte puede ser requerida directamente por la Comisión, por un Estado, por particulares o por las propias jurisdicciones nacionales.

En cuanto a la naturaleza del requerimiento que puede formularse ante la Corte, éste puede referirse a un contencioso de interpretación de los tratados y actos comunitarios; contencioso de anulación de los actos comunitarios (por exceso de poder; contencioso para determinar la responsabilidad extracontractual y contencioso de represión o control en materia de libre competencia y otras relativas al mercado común del carbón y del acero.

- El Tribunal de Justicia del Acuerdo de Cartagena, Paolillo, F. "El Tribunal de Justicia del Acuerdo de Cartagena". Perspectivas del Derecho Internacional Contempordneo". Loc. cit., 1981, pp. 109-127) inserto dentro de este acuerdo subregional andino, posee competencias:

a) cuando se impugna la legalidad de ciertos actos de la Comisión o de la Junta, incluso por desviación de poder (acción de nulidad);

b) cuando se presenta una reclamación contra un Pa ís Miembro por incumplimiento de las obligaciones emanadas del ordenamiento jurídico del Acuerdo (acción de incumplimiento); y 
c) cuando se le requiera la interpretación de las normas de dicho orden jurídico por vía de interpretación prejudicial, a solicitud de cualquier juez nacional que deba aplicar una norma de derecho comunitario para decidir en un proceso.

c) Finalmente, debe mencionarse la creación de un Tribunal Internacional de Derecho del Mar en virtud de la Convención de las Naciones Unidas sobre el Derecho del Mar, 1982, no-vigente.

Competencias. - De acuerdo con la Parte XV y el Anexo VI de la Convención, el Tribunal estará encargado de conocer de las controversias relativas a la interpretación o la aplicación de esta Convención, así como de otros acuerdos internacionales concernientes a los fines de ese instrumento que les sometan.

Esta competencia puede ser limitada por los Estados partes haciendo uso de las "excepciones facultativas" que la Convención acepta taxativamente en los Arts. 297 y 298. Aún más, un Estado parte en la Convención puede declarar que para la solución de las controversias derivadas de ese instrumento acepta la jurisdicción de la Corte Internacional de Justicia o el arbitraje conforme al Anexo. Esta opción restringe el número de Estados respecto de los cuales el Tribunal poseerá competencia obligatoria.

El Tribunal puede funcionar en pleno (21 miembros) o en Salas (Art. 15, Anexo VI). Se prevé la posibilidad de constituir una Sala de Procedimientos Sumario. Para conocer de los litigios relativos a los Fondos Marinos, se constituye una Sala de Controversias de los Fondos Marinos, integrada por 11 miembros del Tribunal, que también podrá ejercer competencia consultiva. La Sala de Controversias de Fondos Marinos constituirá una Sala ad hoc, integrada por tres de sus miembros para conocer de las controversias que surjan entre un Estado Parte y la Autoridad relativa a actos u omisiones de la Autoridad o de un Estado Parte que se alegue que constituyen una violación de la Parte XI o sus anexos, o de las normas, reglamentos y procedimientos de la Autoridad, o actos de la Autoridad que se alegue constituyen una extralimitación en el ejercicio de su competencia o una desviación de poder (Art. 188, 1, b). Las controversias entre Estados Partes relativas a la Parte XI y sus anexos pueden someterse por acuerdo entre ellas 
a una sala especial del Tribunal Internacional del Derecho del Mar (Art. 288, 1).

Ratione Personae.- No sólo los Estados Partes pueden comparecer ante el Tribunal, sino que además la Autoridad, la Empresa, las empresas estatales y las personas naturales o jurídicas que operen en asociación con la Autoridad.

Este Tribunal, de entrar en funcionamiento, constituirá una jurisdicción especializada e innovadora dentro del Derecho Internacional Contemppráneo. 